\title{
Patterns
}

\section{The impact of public acceptance on cost efficiency and environmental sustainability in decentralized energy systems}

\section{Highlights}

- Determine cost-optimal energy systems of 11,131 German municipalities in $\mathbf{2 0 5 0}$

- Combine cluster and regression analyses with mathematical optimization methods

- Apply nationwide scenicness data to estimate the landscape impact of onshore wind

- Rejecting onshore wind leads to a significant increase in costs and $\mathrm{CO}_{2}$ emissions

\section{Authors}

Jann M. Weinand, Russell McKenna, Max Kleinebrahm, Fabian Scheller, Wolf Fichtner

\section{Correspondence}

jann.weinand@kit.edu

\section{In brief}

We employ a novel combination of geospatial, cluster, regression, and optimization methods to estimate national impact of public acceptance for onshore wind turbines on the energy systems of over 11,000 German municipalities. Depending on the location of the municipality and the scenicness of its landscape, the energy systems may be associated with a significant increase in costs and $\mathrm{CO}_{2}$ emissions by 2050 . 


\title{
Article
}

\section{The impact of public acceptance}

on cost efficiency and environmental sustainability in decentralized energy systems

\author{
Jann M. Weinand, ${ }^{1,4,{ }^{*}}$ Russell McKenna, ${ }^{2}$ Max Kleinebrahm, ${ }^{1}$ Fabian Scheller, ${ }^{3}$ and Wolf Fichtner ${ }^{1}$ \\ ${ }^{1}$ Chair of Energy Economics, Institute for Industrial Production (IIP), Karlsruhe Institute for Technology, 76131 Karlsruhe, Germany \\ ${ }^{2}$ Chair of Energy Transition, School of Engineering, University of Aberdeen, King's College, Aberdeen AB24 3FX, UK \\ ${ }^{3}$ Energy Economics and System Analysis, Division of Sustainability, Department of Technology, Management and Economics, Technical \\ University of Denmark, Matematiktorvet, 2800 Kgs. Lyngby, Denmark \\ ${ }^{4}$ Lead contact \\ ${ }^{*}$ Correspondence: jann.weinand@kit.edu \\ https://doi.org/10.1016/j.patter.2021.100301
}

THE BIGGER PICTURE Renewable energy technologies are necessary to maintain secure energy supplies and limit the impacts of climate change. Developments of these technologies are mostly planned purely based on economic criteria, but this can lead to resistance in local communities. Among the diverse renewable technologies, especially onshore wind turbines may negatively affect the scenicness of beautiful landscapes. We analyze how cost-efficient local energy systems could be impacted through public opposition toward onshore wind. In doing so, we draw on a database of public evaluation of landscape beauty across Germany. In the energy systems of German municipalities with high scenicness, onshore wind would mainly be replaced by solar photovoltaics. Depending on the location, the local energy systems may be associated with a significant increase in costs and $\mathrm{CO}_{2}$ emissions. These insights can support local and national stakeholders in making decisions relating to energy and climate policy.

123015 Development/Pre-production: Data science output has been

rolled out/validated across multiple domains/problems

\section{SUMMARY}

Local resistance often hinders renewable energy technology developments, especially for onshore wind. In decentralized energy systems, the landscape impact of wind turbines or transmission lines is a key barrier to public acceptance. By using landscape scenicness as a proxy for public acceptance, we quantify its impact on the optimal energy systems of 11,131 German municipalities. In municipalities with high scenicness, it is likely that onshore wind will be rejected, leading to higher levelized costs of energy by up to about $7 €$-cent/ kWh. Onshore wind would be replaced mainly by solar photovoltaics and imports, and the cost-optimal energy systems would be associated with higher $\mathrm{CO}_{2}$ emissions of up to about $200 \mathrm{gCO}_{2} / \mathrm{kWh}$ compared with an average of around $50 \mathrm{gCO}_{2} / \mathrm{kWh}$. The findings help to identify municipalities where public resistance to onshore wind could be particularly high and support the scientific and policy debate about the location of onshore wind farms.

\section{INTRODUCTION}

In line with the Paris Agreement, about 190 countries aim to limit global warming to well below $2^{\circ} \mathrm{C} .{ }^{1}$ Meeting this objective requires a substantial transformation of the energy system with a strong expansion of renewable energy (RE) sources. Due to the decentralized character of these sources, local energy plan- ning is important for a successful implementation of energy systems with high shares of RE. ${ }^{2}$ Internationally, many local initiatives are in place, with exemplar communities in Africa, ${ }^{3}$ North America, ${ }^{4}$ or Europe, ${ }^{5}$ to name but a few. In Europe, the "Covenant of Mayors" is the mainstream movement, involving local authorities that voluntarily commit to increase renewable energies on their territory. ${ }^{6}$ In 2018 the Covenant 


\begin{tabular}{llllll}
\hline \multicolumn{2}{l}{ Table 1. Characteristics of the ten representative German } & municipalities \\
\hline Cluster & Municipality name & $\begin{array}{l}\text { Population density } \\
\left(\text { inhabitants/km }{ }^{2}\right)\end{array}$ & $\begin{array}{l}\text { Residential demand } \\
(\mathrm{GWh} / \mathrm{a})\end{array}$ & $\begin{array}{l}\text { Commercial demand } \\
(\mathrm{GWh} / \mathrm{a})\end{array}$ & $\begin{array}{l}\text { Industrial demand } \\
(\mathrm{GWh} / \mathrm{a})\end{array}$ \\
\hline 1 & Gelbensande & 48 & $2.73(+0.03)$ & $2.93(+0.03)$ & $17.70(+0.01)$ \\
2 & Bad Kreuznach & 882 & $64.27(+0.91)$ & $89.37(+1.32)$ & $57.60(+0.38)$ \\
3 & Dänischenhagen & 244 & $8.06(+0.04)$ & $7.03(+0.04)$ & $9.67(+0.02)$ \\
4 & Warnow & 22 & $2.15(-0.01)$ & $1.67(-0.01)$ & $21.37(+/-0)$ \\
5 & Seckach & 148 & $6.03(-0.04)$ & $7.54(-0.04)$ & $16.07(+/-0)$ \\
6 & Trebsen/Mulde & 110 & $9.23(-0.07)$ & $6.99(-0.06)$ & $19.96(-0.02)$ \\
7 & Nindorf & 43 & $1.22(-0.01)$ & $1.10(-0.01)$ & $7.27(+/-0)$ \\
8 & Rövershagen & 125 & $3.84(+0.03)$ & $4.78(+0.04)$ & $11.48(+0.01)$ \\
9 & Göhrde & 0 & $0.00(+/-0)$ & $0.00(+/-0)$ & $25.75(+/-0)$ \\
10 & Steinbergkirche & 77 & $6.15(-0.02)$ & $4.98(-0.03)$ & $19.09(-0.01)$ \\
\hline
\end{tabular}

Representative municipalities are those with the smallest deviation from the cluster center across 38 socio-energetic indicators from the cluster analysis in Weinand et al. ${ }^{23}$ The estimated annual change in residential, commercial, and industrial electricity demand is shown in parentheses.

of Mayors already included about 7,850 local authorities and 250 million inhabitants. ${ }^{7}$

Besides the technical, environmental, and social conditions through decentralization, governance challenges arise: many more actors now play important roles in energy system planning, and new dynamics complicate the tasks of authorities in planning the energy system transition. ${ }^{8}$ This is especially true for community energy, when local community participation is emphasized through ownership and control of renewable energies. ${ }^{9}$ A growing number of local energy conflicts around onshore wind power and power grid extensions affect the plans of the energy transition. ${ }^{10}$ There is wide international evidence that resistance toward onshore wind is mainly related to the impact on the scenery of the landscape,${ }^{11-14}$ but the subjective nature of public acceptance or landscape esthetics makes quantifying these aspects and obtaining reliable data a major challenge. $^{15}$

Some studies have already attempted to quantify the impact of landscape esthetics in energy system analyses. Wehrle et al. ${ }^{16}$ demonstrated that not disturbing landscapes, i.e., by using solar plants instead of wind turbines, comes with high additional costs for the German and Austrian energy systems. While landscape esthetics was used as motivation for Wehrle et al., ${ }^{16}$ they were not included as an influencing factor in their analysis. In a recent study, the relationship between onshore wind potential and scenicness values in Great Britain has been explored. ${ }^{17}$ The article showed that the rejection of onshore wind energy projects is strongly related to the scenicness of the landscape: the more scenic a landscape, the more likely the wind energy project will be rejected. In the cited article, however, only the technically feasible onshore wind potential was evaluated economically and not investigated as part of a holistic energy system. In a further study, ${ }^{18}$ the effect of public acceptance for onshore wind on the national energy system in Great Britain was investigated, demonstrating that costs could increase by about $14 \%$ if public sensitivity to visual impacts is high. However, as the community level is a key example for resistance toward onshore wind, ${ }^{19} \mathrm{a}$ study quantifying the impact at this local level is needed. The investigation of energy systems at this level is important, as local stakeholders are willing to accept new wind turbines in their vi- cinity if they can participate in the decision making, if the turbines are owned by the community and if the electricity is consumed in the region and not exported. ${ }^{20,21}$

With regard to the above-mentioned participation in decision making, citizens especially prefer to receive information about the planned projects. ${ }^{22}$ Therefore, the present article aims to inform local decision makers about the implications of their resistance toward onshore wind on local energy system design, costs and $\mathrm{CO}_{2}$ emissions. The study quantifies the landscape impact, a significant part of public acceptance for onshore wind, on optimal decentralized energy systems for the first time, with a case study in Germany. The experimental procedures section gives a precise definition of public acceptance in this context. Based on a cluster classification ${ }^{23}$ of the 11,131 German municipalities regarding their suitability for decentralized energy systems, 10 representative municipalities are selected (cf. Table 1). The cost-optimal long-term energy system transformation of these municipalities until 2050 is designed using an energy system optimization model. The year 2050 was chosen as the target year in order to reflect the investment decisions until that date, which is of relevance for the objective of the European Union to achieve net-zero greenhouse gas emissions. ${ }^{24}$ With the help of a Gaussian process regression, the results of these case studies are then transferred to all other 11,131 municipalities. By applying the new and first dataset on scenicness of landscapes for the whole territory of Germany, ${ }^{25}$ the effect of public acceptance for onshore wind on the optimal decentralized German energy systems is subsequently examined. In municipalities with scenicness values above a certain threshold, onshore wind is excluded as an option in the energy system analyses, in order to estimate the effects on costs and $\mathrm{CO}_{2}$ emissions. The first (4.15), second (4.98), and third quartiles (5.86) of the scenicness values (cf. Figure 1) are used to define the following scenarios:

- Reference Scenario: wind power is not restricted by scenicness.

- Scenario NoWind: wind power is completely excluded. This Scenario is only relevant for the comparison of the optimal energy system design for the cluster centers with and without wind. 

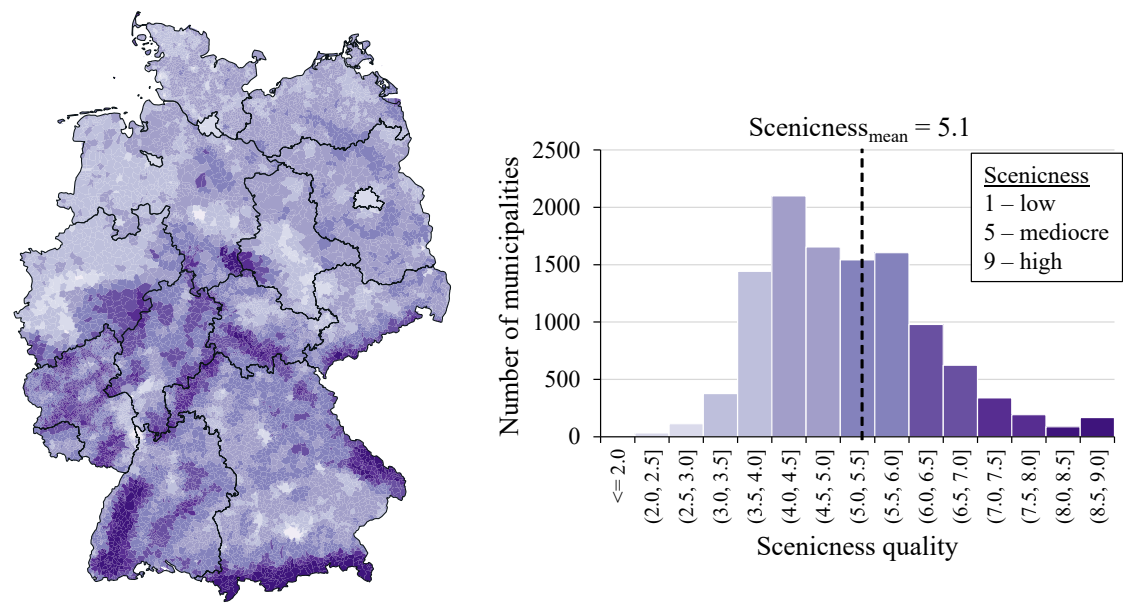

Figure 1. Mean scenicness quality in 11,131 German municipalities

The original scenicness values are taken from Roth et al. ${ }^{25}$ The colors in the map of Germany quantify the beauty of the landscapes according to the coloring of the scenicness values in the histogram.

the share of renewable energies in electricity supply in the cluster centers in 2050 decreases between around 0\% (clusters 7 and 10) and 100\% (cluster 9) and on average by $30.6 \%$. In Göhrde (cluster 9), no RE plants are installed at all in the NoWind Scenario due to missing renewable potentials besides wind.

In general, Figure 4 demonstrates that the share of renewable energies in elec-

- Scenarios NoWind_75\%, NoWind_50\%, and NoWind 25\%: wind power is excluded in municipalities with a mean scenicness quality of at least $4.15,4.98$, or 5.86 , respectively. The percentage values in the scenario names refer to the quartiles.

By combining cluster analysis, mathematical optimization techniques and regression analysis, as well as datasets from multiple disciplines (cf. Figure 2) the developed methodology makes an important contribution to the energy and data science communities.

\section{RESULTS}

Impact of public acceptance on the optimal energy system design

Integrating high shares of renewable energies into the energy system remains one of the major challenges of the energy transition. As an approach to addressing this, this study employs the $\mathrm{RE}^{3} \mathrm{ASON}$ (Renewable Energies and Energy Efficiency Analysis and System Optimization) energy system optimization model ${ }^{26}$ described in the experimental procedures, which optimizes investments and dispatch of the energy systems (cf. Figure 3 for a model overview and Tables 2-4 for the included sets, parameters, and variables). The resulting cost-optimal energy systems of the representative German municipalities in the Reference Scenario are characterized by a large share of wind power (cf. Figure 4A). The only exceptions are the cluster centers of clusters 2,7 , and 10 with limited or no technical wind potential due to minimum distance restrictions from inhabited and protected areas. In cluster 2, characterized by large German cities, there is only a limited wind potential due to minimum distance regulations for wind and low land availability. Instead, the power supply is mainly provided by solar photovoltaics (PV) due to the large roof area availability.

In the NoWind Scenario (cf. Figure 4B), the lack of electricity supply by wind power is mainly being replaced by PV, wasteto-energy, and wood combustion biomass plants, as well as electricity imports. In cluster 3 , which has a high potential for deep geothermal energy, onshore wind is substituted primarily by geothermal plants. Compared with the Reference Scenario, tricity supply will rise steadily until 2050 in both scenarios, caused by the decreasing costs of renewable energies and storages, as well as by the increasing costs of electricity procurement and transmission. Assuming that the energy systems of all municipalities in the clusters would follow the same development as the optimized energy systems of the cluster centers, the share of renewable energies in Germany's electricity mix would increase from the currently around $40 \%$ in $2019^{27}$ to $88 \%$ (Reference Scenario) or $68 \%$ (NoWind Scenario). The share of onshore wind would change from $17 \%$ to $63 \%$ (Reference Scenario), of PV from $8 \%$ to $21 \%$ (Reference Scenario) or 55\% (NoWind Scenario) and of biomass from $8 \%$ to $4 \%$ or $7 \%$, respectively. The electricity supply could even be $100 \%$ renewable if imports are covered by other renewables as offshore wind and hydropower (shares of $4 \%$ and $3 \%$ in 2019). ${ }^{27}$ It should be noted that these aggregated values for the whole of Germany are of a theoretical nature. This is because the results are cost optimal from the perspective of a municipal planner without taking into account interactions with other municipalities or the effect on the surrounding/national energy system.

At the same time, average $\mathrm{CO}_{2}$ emissions in municipal energy systems are declining. In the Reference Scenario, due to the increased electricity exports resulting from volatile renewable electricity generation, even negative emissions are achieved by 2050 in municipalities with wind potential. In Göhrde (cluster 9) in the NoWind Scenario, $\mathrm{CO}_{2}$ emissions are so low despite $100 \%$ electricity imports because, on the one hand, the specific emissions from electricity imports decline sharply by 2050 (see the experimental procedures). On the other hand, there is no heat sector in the optimization for this municipality due to the absence of inhabitants, and therefore no gas or oil is imported. For more information on the energy balances in the various energy systems, please refer to the supplemental information (Figures S1 and S2).

Impact of public acceptance on costs and emissions The energy systems of the three cluster centers, 2, 7, and 10, with limited or no wind power potential are associated with the highest levelized cost of energy (LCOE) in the Reference Scenario (cf. Table 5). The LCOEs in the ten cluster centers range from $8.9 €$-cent/kWh (cluster 9 ) to $19.3 €$-cent/kWh 


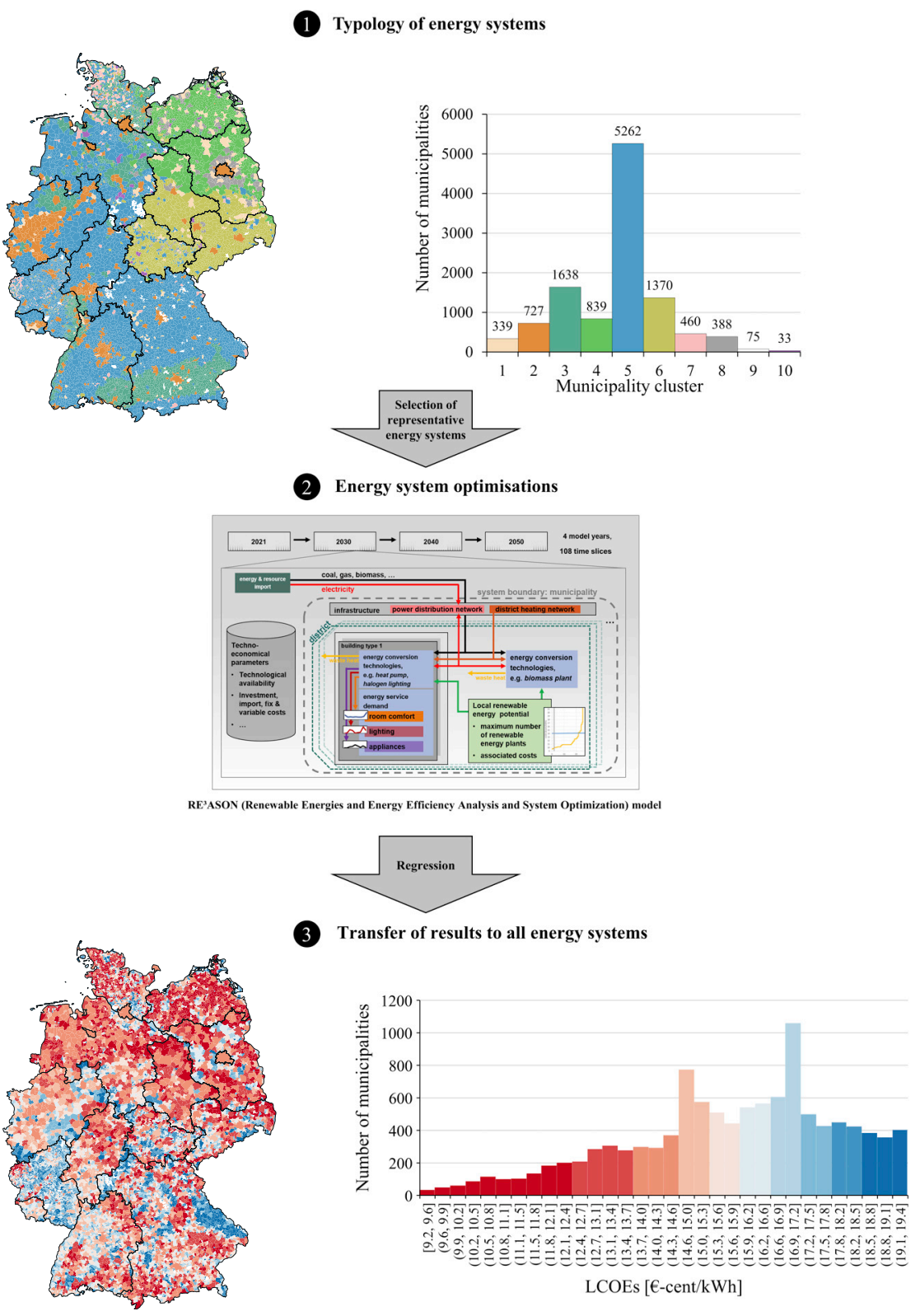

Figure 2. Methodology of the case study In the first step, representative clusters for the 11,131 German municipalities are identified. The results of the cluster analysis (upper map of Germany) are from Weinand et al. ${ }^{23}$ The colors in the histogram refer to the clusters in the map. In the next step, the energy systems of the cluster centers of these clusters are optimized in the energy system optimization model $\mathrm{RE}^{3} \mathrm{ASON}$. The transfer of optimization results to all municipalities is performed in the third step, using a regression model. The lower map of Germany shows the regression results for the LCOEs in the Reference Scenario. The colors of the municipalities refer to the colors in the histogram.

prices can be found in the supplemental information (Figure S3), but they do not show a trend contradicting the above statements.

Transferring the LCOEs of the ten representative municipalities in the Reference Scenario to all German municipalities using a Gaussian process regression results in LCOEs between 9.2 and $19.4 € €$-cent/ $\mathrm{kWh}$ with a mean value of $15.7 €$-cent/ $\mathrm{kWh}$. The geographical distribution of the LCOEs among the municipalities is shown in Figure 2. LCOEs are particularly high in energy systems with very low technical onshore wind potential. Whereas an average technical onshore wind potential of approximately $2 \mathrm{GWh} /\left(\mathrm{a} \cdot \mathrm{km}^{2}\right)$ is present in German municipalities, this potential is only $0.9 \mathrm{GWh} /\left(\mathrm{a} \cdot \mathrm{km}^{2}\right)$ on average for $\mathrm{mu}$ nicipalities with LCOEs above $18.0 €$ cent/kWh and only $0.2 \mathrm{GWh} /\left(\mathrm{a} \cdot \mathrm{km}^{2}\right)$ on average for municipalities with LCOEs above $19.0 €$-cent/kWh.

At an average of 13.4 and $14.0 €$-cent/ $\mathrm{kWh}$, the LCOEs are particularly low in the municipalities of cluster 4 and cluster 7 . This seems plausible, since these municipalities have the highest potential for RE

(clusters 2 and 10). If wind is excluded as an energy supply technology in the cluster centers in the NoWind Scenario, the LCOEs of the energy systems increase by up to $65 \%$ (cf. Table 5) and range from $14.7 €$-cent/kWh (cluster 9 ) to $23.0 €$-cent/ kWh (cluster 3). The LCOEs increase particularly in those municipalities whose energy system is characterized by a very high share of wind power in the Reference Scenario (cf. clusters 1, 4, and 9 in Table 5 and Figure 4). In the city of Bad Kreuznach (cluster 2), as well as Nindorf (cluster 7) and Steinbergkirche (cluster 10), the LCOEs change only slightly or not at all due to low or no wind power potential, respectively. $\mathrm{CO}_{2}$ emissions in the cost-optimal energy systems of the cluster centers are also higher in the NoWind Scenario and, in contrast to the Reference Scenario, no negative emissions occur (cf. Figure 4B). Sensitivity analyses regarding costs and in Germany. ${ }^{23}$ The mean LCOEs in cluster 5 (16.2 €-cent/ $\mathrm{kWh}$ ), cluster 8 (16.2 €-cent/kWh), and cluster 6 (15.9€cent/kWh) are above the German average. While the municipalities in cluster 5 have a rather low potential for renewable energies, Weinand et al. ${ }^{23}$ classified this potential as medium to high for cluster 6 and cluster 8 . However, this assessment for clusters 6 and 8 is mainly based on the very high technical potential for deep geothermal energy. As Figure 4A shows, however, this technology is not part of the optimal energy system in these municipalities due to very high installation costs.

The number and location of municipalities affected by the restriction of onshore wind due to the scenicness thresholds vary in the scenarios NoWind_75\%, NoWind_50\%, and NoWind_25\% (cf. Table 6 and Figure 5). While in scenario 


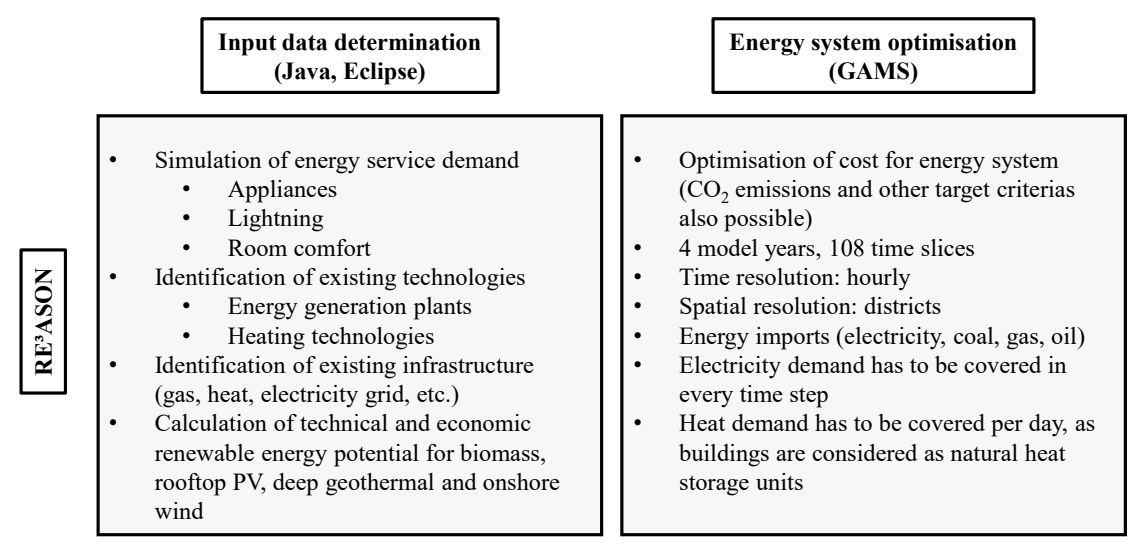

Figure 3. Overview of the two parts of the $\mathrm{RE}^{3}$ ASON model
NoWind_75\% the municipalities are also partly located in northern Germany, in scenario NoWind_25\% only municipalities in central and southern Germany are affected. Thus the north with the highest potential for wind energy ${ }^{28}$ would be less affected by an exclusion of wind energy due to public acceptance. This is also demonstrated by the share of onshore wind potential, which is lower than the share of German municipalities in the three scenarios in Table 6: while in the NoWind_75\% scenario $75 \%$ of the German municipalities contain $62.7 \%$ of the onshore wind potential, in the NoWind_25\% scenario the share is only $13.1 \%$. The share of energy demand is also lower than the share of municipalities in each scenario. This is due to the fact that, in the large German cities, which account for a large part of Germany's energy demand, the scenicness is very low (cf. Figure 1).

The $\Delta$ LCOEs resulting in all German municipalities in Scenarios NoWind_75\%, NoWind_50\%, and NoWind_25\% compared with the Reference Scenario are between 0 and $7.3 €$-cent/kWh (cf. Figure 5). The possible impact of public acceptance for onshore wind on the $\triangle$ LCOEs is thereby dependent on the onshore wind potential: in 551 German municipalities with $\Delta$ LCOEs less than or equal to $0.01 €$-cent $/ \mathrm{kWh}$, the technical onshore wind potential is on average only $0.02 \mathrm{GWh} /\left(\mathrm{a} \cdot \mathrm{km}^{2}\right)$, which is particularly low compared with the German average of $2.00 \mathrm{GWh} /\left(\mathrm{a} \cdot \mathrm{km}^{2}\right)$. The share of municipalities with $\Delta$ LCOEs at 0 increases from $5.8 \%$ in Scenario NoWind_75\% to $12.4 \%$ in Scenario NoWind_25\% (cf. Table 6). Likewise, the mean $\triangle$ LCOEs decrease from 2.73 to $2.09 €$-cent/kWh. This is also related to the fact described above, that increasing scenicness is accompanied by a reduction in wind potential, thus having less impact on $\Delta$ LCOEs. This is partly due to the fact that the highest scenicness qualities are found in mountainous regions. These regions are excluded when determining onshore wind potential since they are hardly suitable for wind due to technical and fluid-mechanical factors. ${ }^{28}$ Nevertheless, the influence of public acceptance is not negligible even in the NoWind_25\% scenario. In total, an additional annual cost of about 4.7 billion euro could result by 2050 in the municipalities of the NoWind_25\% Scenario.

The trend in $\Delta \mathrm{CO}_{2}$ compared with the Reference Scenario is similar to that of $\Delta \mathrm{LCOEs}$, with declining mean $\Delta \mathrm{CO}_{2}$ of 74.2 , 65.6 , and $56.8 \mathrm{gCO}_{2} / \mathrm{kWh}$ in the scenarios NoWind_75\%, NoWind_50\%, and NoWind_25\%, respectively (cf. Table 6 and Figure S5 for a geographical distribution). In scenario NoWwith high scenicness by the public would occur primarily in the southern regions of Germany (cf. Figure 5). This assumption correlates with the current German onshore wind turbine stock: turbines are currently only present in 3,170 (28.5\%) of German municipalities. The mean scenicness in municipalities with these wind turbines is 4.29 , i.e., well below the average scenicness of 5.1. It is important to note that, due to minimum distance specifications, wind turbines are unlikely to be installed at sites with a scenicness of 1 or 2 , as these are mainly built-up areas. In relation to the scenarios NoWind_75\% to NoWind_25\%, only $44 \%$ of the existing turbines are in municipalities with a scenicness above the first quartile of $4.15,20 \%$ in municipalities above the second quartile of 4.98 , and only $7 \%$ above the third quartile of 5.86. This again demonstrates that the scenicness could affect the approval of onshore wind projects. The existing wind turbines are mainly located in the federal states in the north with 19.8 turbines per $1,000 \mathrm{~km}^{2}$ in Schleswig Holstein and 13.0 turbines per $1,000 \mathrm{~km}^{2}$ in Lower Saxony and Brandenburg. In contrast, only 1.7 turbines per $1,000 \mathrm{~km}^{2}$ and only 2.2 turbines per $1,000 \mathrm{~km}^{2}$ are installed in the southern federal states, Bavaria and Baden-Württemberg, respectively. This is probably due to the higher capacity factors at the coast in the north of Germany, ${ }^{30}$ but could also be related to the beautiful landscapes in the south (cf. Figure 1), which could indicate higher resistance toward onshore wind. ${ }^{31}$

\section{DISCUSSION}

\section{Limitations}

The results shown in this study are cost optimal from the perspective of a municipal central planner. Especially the results aggregated at national level should therefore be interpreted with caution. By neglecting interactions between municipalities, such as the simultaneous optimization of the energy systems of neighboring municipalities, the LCOEs may have been overestimated. The global cost optimum could be found at a higher level: Tröndle et al. $^{32}$ have shown that system costs can be about $20 \%$ lower for a continental-scale supply than for a regional-scale supply. However, the former would also require a significant expansion of the transmission grid, which in turn could lead to resistance in local society due to the impact on the landscape. ${ }^{25}$ The acceptance of RE expansion is very high at the national level, as is the expansion of the transmission grid if it serves to increase 


\begin{tabular}{ll}
\hline Table 2. Nomenclature of sets and subsets \\
\hline Sets and \\
subsets & Description \\
\hline$A Y$ & all years (1880-2050) \\
$B I$ & building instances (of a building type) \\
$E C$ & energy carriers \\
$E C^{b}$ & balanced energy carriers, e.g., electricity \\
$E M$ & emissions \\
$D S$ & all districts \\
$D S^{e n}$ & endogenous districts \\
$D S^{e x}$ & exogenous districts (outside the regions' \\
& boundaries, \\
$M Y$ & for energy import) \\
$S T$ & model years $\{2021,2030,2040,2050\}$ \\
$T C$ & sectors \\
$T C^{s s}$ & technologies \\
$T C^{\prime s}$ & small (building) scale technologies \\
$T C^{f x}$ & large (district) scale technologies \\
$T S$ & technologies with a given generation profile, \\
& e.g., PV \\
& timeslices, i.e., continuous groups of hours \\
& (108 \\
& per year) \\
\hline
\end{tabular}

the share of renewable energies. ${ }^{33}$ However, this translates into acceptance problems as soon as the local level is affected, with landscape modification as the main driving factor. ${ }^{11,33}$ In addition, if onshore wind energy was developed in a centrally coordinated manner, citizens would not or only to a limited extent participate in the projects, which could also lead to problems with project acceptance and, therefore, implementation. ${ }^{21}$ Although probably more cost-effective, implementing the optimal solution for a national system could face many obstacles. Nevertheless, the application of our methodology in national or international energy system analyses, or from a different perspective than that of a central planner, would provide further important insights into the impacts of onshore wind acceptance.

In addition, there are several reasons why this study examined the impact of public acceptance for onshore wind energy rather than solar PV or biomass. Firstly, there is a lot of resistance against onshore wind at the local level, especially through landscape modifications. Therefore, the database on scenicness enables the landscape impact to be quantified, which is a significant aspect of public acceptance. However, the literature also shows that public concern is reduced when the affected individuals live further away from the turbines, ${ }^{34,14}$ or have previous experience with wind energy. ${ }^{35-37}$ If possible, quantification of such aspects would also be pertinent to future energy system analyses. Furthermore, solar PV shows the strongest acceptance among RE technologies, ${ }^{38,39}$ and could also even increase the acceptance of local energy communities. ${ }^{40}$ The impact of solar PV on landscapes is also estimated to be relatively low, ${ }^{41}$ higher scenicness does not lead to the rejection of solar PV projects ${ }^{17}$ and acceptance can be increased by coloring the modules in the color of the surrounding. ${ }^{42}$ There is also rejection in society with regard to biomass, especially in relation to biogas plants associated with the cultivation of maize. ${ }^{43}$ Public acceptance of biogas plants in relation to odor emissions ${ }^{44}$ is the only aspect considered in this study. In the applied energy system model, this is reflected by a minimum distance specification in the main wind direction.

Furthermore, not all available technologies were considered in this study. One example is seasonal storage, such as hydrogen storages based on fluctuating PV or wind energy supply, ${ }^{45,46}$ which could reduce the curtailment of renewable energies. ${ }^{47}$ While this type of storage could lead to a reduction in system costs in both the Reference Scenario and the NoWind Scenario, the consideration of ground-mounted PV would probably be particularly advantageous in the NoWind Scenario.

It is also important to be aware that the results of the optimizations and regression analyses cannot substitute detailed on-site planning of a municipal energy system. While good estimates of the results are provided, some regression results differ more or less from the results of the optimizations (cf. Figures S6 and S7). This approach could be improved by investigating more (representative) municipalities so that the regression analysis can utilize a larger amount of data. In addition, the data from the regression analysis and energy system model should be aligned as much as possible. In this study, for example, highlevel results of renewable potentials from nationwide studies had to be employed, since the geographically higher-resolution methods of the energy system model could only be performed for individual municipalities due to computational constraints. To further improve the methodology, the nationwide potentials could be determined again as a function of scenicness, as was done for Great Britain. ${ }^{17}$ Then, these potentials could be used for different scenicness thresholds in the regression instead of completely excluding wind in municipalities with a certain mean scenicness. All these limitations remain as possible starting points for future studies.

\section{Quantifying the cost of public acceptance}

In municipalities with high scenicness, the mean LCOEs can be up to about $7 €$-cent/kWh higher if onshore wind is rejected as an energy supply source, and the cost-optimal energy systems would be associated with up to about $220 \mathrm{gCO}_{2} / \mathrm{kWh}$ higher mean emissions. In this case, onshore wind would be replaced mainly by imports, solar PV, and biomass. Wehrle et al. ${ }^{16}$ also showed that not disturbing landscapes by replacing wind capacities with solar PV comes at significant opportunity costs and additional emissions. Furthermore, Ueckerdt et al. ${ }^{48}$ and Scholz et al. ${ }^{49}$ have also already shown that solar PV would be associated with significantly higher system integration costs than onshore wind.

The geographically unequal expansion of the current turbine stock in Germany demonstrated in this study confirms the well-identified trend that the development of onshore wind is primarily determined by generation cost-efficiency and public acceptance. Also, in debates in literature and politics, the cost performance of technologies is usually the main focus. ${ }^{50}$ But this overlooks the relative costs and opportunities, which could emerge for different regions. ${ }^{50}$ Scientific discussions increasingly emphasize that future energy systems should take equity into account, ${ }^{50-52}$ since all regions would benefit from an equal distribution of new installations; for example, 


\begin{tabular}{|c|c|}
\hline Parameters & Description \\
\hline$A F$ & annuity factor \\
\hline$A L_{y, t, t c}^{f x}$ & $\begin{array}{l}\text { activity level for technologies with given } \\
\text { profiles, } \\
\text { e.g., PV }\end{array}$ \\
\hline$C D$ & distribution costs \\
\hline$C E$ & emissions costs \\
\hline CF & fuel costs \\
\hline $\mathrm{Cl}$ & $\begin{array}{l}\text { installation costs, e.g., for a scaffolding for } \\
\text { building insulation }\end{array}$ \\
\hline$C O D$ & electricity demand in commercial sector \\
\hline$C T$ & transmission costs \\
\hline$C V$ & variable costs \\
\hline$c x$ & fix costs \\
\hline$D F$ & discount factor \\
\hline$D M$ & demand for energy services \\
\hline$E M^{e x}$ & $\begin{array}{l}\text { model-exogenous emissions (e.g., from the } \\
\text { transport sector) }\end{array}$ \\
\hline$E R$ & emission rate \\
\hline$F B^{\max }$ & $\begin{array}{l}\text { maximum energy flow from district to } \\
\text { building level }\end{array}$ \\
\hline$F B^{\min }$ & $\begin{array}{l}\text { maximum energy flow from building to } \\
\text { district level }\end{array}$ \\
\hline$F D^{\max }$ & maximum energy flow between districts \\
\hline$H G$ & geographical hierarchy \\
\hline IND & electricity demand in industrial sector \\
\hline 10 & input/output rates for technology processes \\
\hline$I S^{B I} / I S^{D S *}$ & initially installed number of units (stock) \\
\hline $\mathrm{NH}$ & number of hours per timeslices \\
\hline$N T$ & quantity of a timeslice per year \\
\hline$N B$ & $\begin{array}{l}\text { number/quantity/scale factor for this } \\
\text { building type }\end{array}$ \\
\hline$N Y$ & $\begin{array}{l}\text { number of years that are represented by a } \\
\text { model year }\end{array}$ \\
\hline PEF & primary energy factor \\
\hline$R L$ & remaining lifetime of an installed technology \\
\hline $\begin{array}{l}U A^{B I} / \\
U A^{D S *}\end{array}$ & maximum number of allowed units \\
\hline UI & investment per unit \\
\hline$W^{c}$ & weighting factor for system costs objective \\
\hline$w^{e}$ & weighting factor for emissions objective \\
\hline$W^{i}$ & $\begin{array}{l}\text { weighting factor for energy imports } \\
\text { objective }\end{array}$ \\
\hline$W^{p}$ & $\begin{array}{l}\text { weighting factor for primary energy } \\
\text { objective }\end{array}$ \\
\hline
\end{tabular}

through the creation of jobs and regional value added. These studies aim to demonstrate that limiting emerging regional inequalities would foster the implementation success of the energy transition toward systems with large RE capacities. While a minimization of system costs leads to spatially concentrated impacts, costs are higher but more evenly distributed when regional equity is maximized. ${ }^{51,52}$ While the former statement is certainly correct from the perspective of planners of national or international energy systems (as analyzed in these studies), it does not agree with our results from the perspective of a regional planner. On the contrary, from the point of view of the regional energy system planner, the system costs are lower when onshore wind is installed, regardless of geographical location.

Due to the trade-off between equity and efficiency, which is also present in Germany, ${ }^{53}$ the amendment of the German Renewable Energy Sources Act in 2016 introduced a tender mechanism in which only the offers of the most cost-effective producers are accepted. To ensure that less windy sites in central and southern Germany can more or less compete with windy sites in the north, the actual remuneration is multiplied by a correction factor that is higher for less windy sites than for more windy sites. This should lead to a more even spatial distribution of wind turbines than would be possible on the basis of a purely efficiency-based approach. ${ }^{53}$ However, as the results of this study confirm, the cost and equity consideration in energy system analyses must be extended to include the dimension of public acceptance: despite the advantage of an equal distribution of wind turbines, some regions still refuse to install them. Similar to the World Energy Trilemma ${ }^{54}$ with the three dimensions "energy security," "energy equity," and "environmental sustainability," a trilemma for the expansion of renewable energies, particularly onshore wind, could be derived from the above discussion. The most important dimensions in this case (according to our analysis), which influence each other, would be "cost-efficiency," "equity," and "local public acceptance." If, for example, a cost-efficient expansion of renewable energies is favored, equity and local public acceptance would be mostly neglected. The three dimensions refer to the planning from the view of a central national decision maker.

Especially with regard to the German government's plans to significantly increase onshore wind capacity by 2030 and $2050,{ }^{55}$ the aspects discussed above must be considered. An expansion of wind capacity is not only relevant from a social perspective, but also from a technical one: in Germany, more than 5 TWh of renewable electricity was curtailed in $2019^{56}$ (in 2010: $0.1 \mathrm{TWh}$ ), ${ }^{57}$ as the majority of turbines are located in the north with low energy consumption and therefore also restricted network capacity. This requires an expansion of the transmission grid in Germany to transmit the large amounts of energy to other regions, such as the south. The quantitative basis of this study, based on the scenicness data by Roth et al., ${ }^{25}$ shows in which municipalities public resistance to onshore wind could be particularly high. Second, the findings regarding the increase in costs and emissions add to the body of literature on this topic, and efforts can be made to convince stakeholders in municipalities of the potential benefits of onshore wind installations. In addition, local or national support mechanisms, such as benefit payments ${ }^{58}$ or acceptance costs, ${ }^{59}$ can be developed on this basis to support the diffusion of onshore wind in these municipalities. An idea of the German government to allow municipalities to participate in the profit of onshore wind turbines (by prescribing an annual payment of the wind farm operator to the municipality) and thereby increase the acceptance has already been under discussion for some time. ${ }^{60}$ 


\begin{tabular}{|c|c|}
\hline $\begin{array}{l}\text { Decision variables - } \\
\text { dispatch and } \\
\text { (de-)commissioning }\end{array}$ & Description \\
\hline$a l^{B I} / a l^{D S}$ & activity level of a technology \\
\hline$u c^{B l} / u c^{D S}$ & commissioned units \\
\hline$u d^{B I} / u d^{D S}$ & endogenously decommissioned units \\
\hline \multicolumn{2}{|c|}{ Binary decision variables } \\
\hline$b n i^{B I} / b n i^{D S}$ & $\begin{array}{l}\text { whether a new investment is made } \\
\text { (binary) }\end{array}$ \\
\hline$b t i^{B l}$ & $\begin{array}{l}\text { whether a technology is installed } \\
\text { (binary) }\end{array}$ \\
\hline \multicolumn{2}{|l|}{ Energy flow variables } \\
\hline$f l^{d}$ & energy flow between districts \\
\hline$f l^{b}$ & $\begin{array}{l}\text { energy flow from district to building } \\
\text { level }\end{array}$ \\
\hline \multicolumn{2}{|l|}{ Stock variables } \\
\hline$u d a^{B I} / u d a^{D S}$ & $\begin{array}{l}\text { all decommissioned units (including } \\
\text { those from the stock that fade out } \\
\text { over time) }\end{array}$ \\
\hline$u s^{B l} / u s^{D S}$ & units in stock/installed units \\
\hline \multicolumn{2}{|c|}{ Cost and emission accounting } \\
\hline$c^{e i}$ & energy import costs \\
\hline$c^{e t}$ & transmission grid costs \\
\hline$c^{e d}$ & energy distribution costs \\
\hline$c^{i a}$ & investment annuities costs \\
\hline$c^{f x}$ & fix unit costs \\
\hline$c^{v r}$ & variable unit costs \\
\hline$c^{e m}$ & emission costs \\
\hline em & endogenous emissions \\
\hline \multicolumn{2}{|c|}{ Objective function values } \\
\hline$z$ & combined objective \\
\hline$z^{c}$ & total discounted system costs \\
\hline$z^{e}$ & total discounted $\mathrm{CO}_{2}$ emissions \\
\hline$z^{i}$ & total discounted net energy imports \\
\hline$z^{p}$ & total discounted primary energy use \\
\hline
\end{tabular}

\section{EXPERIMENTAL PROCEDURES}

Resource availability

Lead contact

Further information and requests for resources should be directed to and will be fulfilled by the lead contact, Jann M. Weinand (jann.weinand@kit.edu).

Materials availability

No materials were used in this study.

Data and code availability

Original data have been deposited to Figshare: https://doi.org/10.6084/m9. figshare.14036189.v1.

\section{Case study}

The general methodology applicable to analyses of various energy systems can be found in the supplemental information. In this paper, the energy systems of the 11,131 German municipalities are the subject of investigation. The transfer of the general methodology from Figure $\mathrm{S} 4$ to this case is shown in Figure 2. In Weinand et al., ${ }^{23}$ a typology for German municipalities was created on the basis of 38 socio-energetic indicators by means of a hierarchical agglomerative cluster analysis. The number of clusters was determined us- ing various cluster validation criteria, such as duda, ${ }^{61}$ ptbiserial, ${ }^{62,63}$ or dunn.${ }^{64}$ The resulting ten municipal clusters differ significantly with regard to the indicators used, such as building age classes or technical RE potentials. RE potentials include technical onshore wind potential, ${ }^{28}$ technical solar energy potential, ${ }^{65}$ technical bioenergy potential, ${ }^{66}$ as well as technical deep geothermal potential. ${ }^{67}$ For a definition of different potentials (geographical, technical, feasible), please refer to McKenna et al. ${ }^{68}$ The technical potential of onshore wind, for example, considers constraints, such as wind turbine characteristics, wind farm array losses, and electrical conversion losses. ${ }^{68}$ When selecting possible locations for onshore wind turbines, minimum distances are maintained, for example, from residential areas due to noise and shadow-flicker. ${ }^{69}$ In the cluster analysis ${ }^{23}$ and the regression in this study, the onshore wind potentials are taken from McKenna et al.., ${ }^{28}$ where the potential is estimated for Germany by matching wind turbines to land use and wind speed classes. When onshore wind potentials in all German municipalities are discussed in the main text of this present article, they are based on McKenna et al. ${ }^{28}$ The indicators and clusters were published open access in Weinand et al. ${ }^{70}$

The cluster analysis in Weinand et al. ${ }^{23}$ indicated that the German municipalities are heterogeneous in terms of size and socio-energetic indicators. "Socio-energetic" indicators refer to social indicators (such as age of persons and buildings, or ownership) that can have an indirect influence on an energy system (e.g., by influencing energy service demands) as well as indicators that have a direct influence on an energy system, such as RE generation potentials. Related to this, the municipalities are suited to varying degrees for decentralized energy systems, due to heterogeneously distributed building classes, industrial companies or RE potentials (for a distribution of the clusters in Germany, see Figure 2). Among the ten municipal clusters, there is a cluster with all major German cities and a very low RE potential (cluster 2). Other municipalities are characterized by a very high RE potential (clusters 4 and 7), some of them especially for deep geothermal energy (cluster 3). Then again, there are municipalities without population (cluster 9) and also municipalities that are rather average in terms of all socio-energetic indicators and form the largest cluster $(5,262$ municipalities) in Germany (cluster 5). The municipalities without population contain, for example, nature reserves or military bases.

In this study, the ten cluster centers ${ }^{23}$ are selected for the optimizations, i.e., the municipality with the smallest deviation from a cluster center across all ( $0-1$ scaled) indicators. Table 1 shows specific characteristics of these municipalities, which are representative of the individual clusters. The energy systems of these ten municipalities are then examined using an optimization model. The $\mathrm{RE}^{3} \mathrm{ASON}$ model ${ }^{26}$ used here is suitable for this purpose since it is completely based on public data and can be applied without manual input collection or input processing. In the optimizations, the electricity demand of the industrial, commercial, and residential consumption sectors must be covered as well as the heat demand of the residential sector. The heat demand of the industrial sector is neglected due to poor data availability. ${ }^{23}$ In $\mathrm{RE}^{3} \mathrm{ASON}$, the total discounted system costs of the energy systems are minimized. When transferring the optimization results to all municipalities, the LCOEs are used as a dependent variable in the regression. For identifying an appropriate regression model, the regression learner from MATLAB is applied.

\section{$\mathrm{RE}^{3} \mathrm{ASON}$ model}

An overview of the two parts "input data determination" and "energy system optimization" of the RE ${ }^{3} \mathrm{ASON}$ model are presented in Figure 3. In the first step of the model ("Input data determination") the required input data are calculated with the use of a Java model (Eclipse). The input data are applied in the second step, the actual optimization model, which is implemented within the General Algebraic Modeling System. The RE ${ }^{3} A S O N$ model consists of several parts, which provide transferable methods for determining the existing technologies, infrastructure, the heat demand of residential buildings, and the electricity demand of industrial, commercial, and residential sectors, as well as the potential and associated costs for energy supply from PV, wind, biomass, and deep geothermal energy in an arbitrary German municipality. Due to the high transferability, the model is applied in this study, as many municipalities in different locations have to be investigated. The input determination, which involves, for example, using satellite data to identify available roof areas and already installed rooftop PV modules, ${ }^{65}$ can take 
A

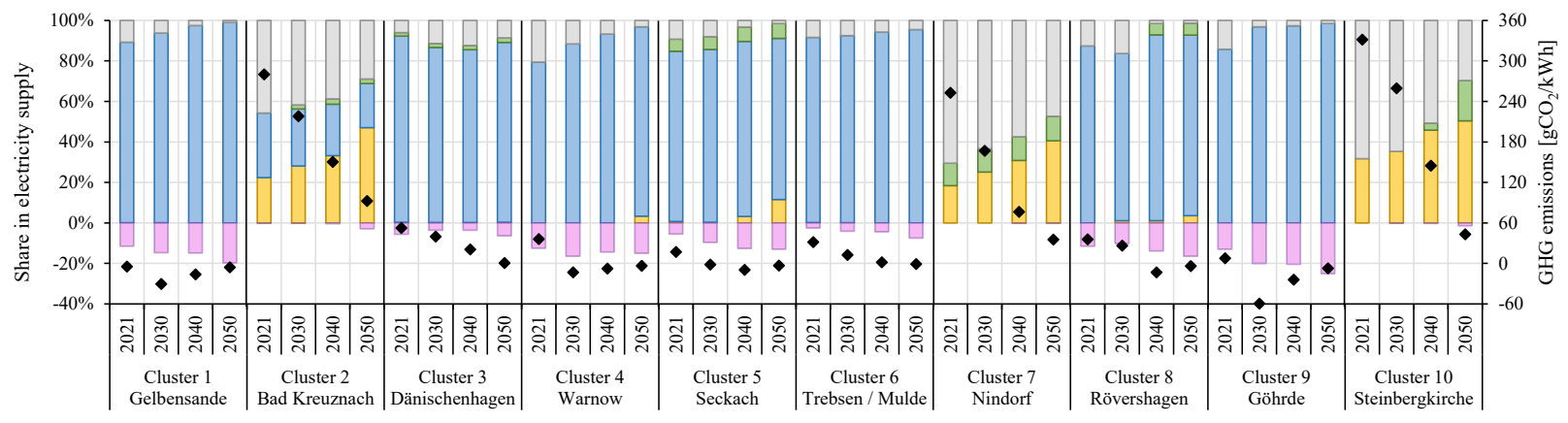

Year and municipality

$\square$ Rooftop PV $\square$ Onshore wind $\quad \square$ Biomass $\quad \square$ Deep geothermal $\square$ Import $\square$ Export $\bullet \mathrm{CO}_{2}$ emissions

B

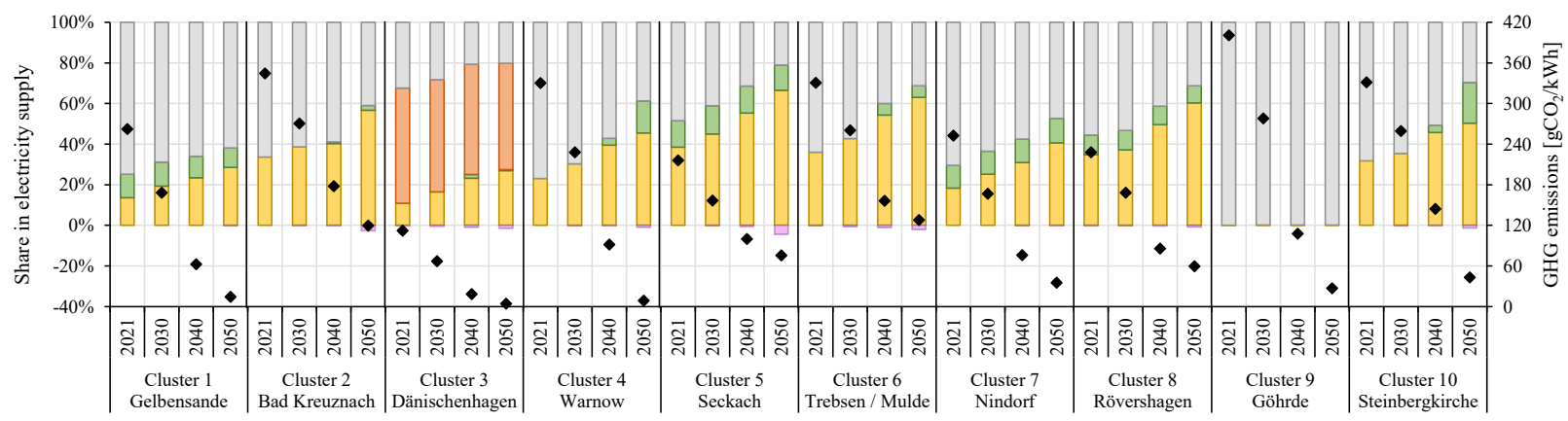

Year and municipality

Figure 4. Electricity supply mix and specific $\mathrm{CO}_{2}$ emissions for the ten cluster centers

The diagrams show the results for the Reference Scenario $(A)$ and the NoWind Scenario $(B)$ in 2021-2050. The entire quantity of generated electricity is taken into account for the generation technologies, regardless of whether it is curtailed, or fed into electricity storages or the grid (exports).

around $15 \mathrm{~h}$ depending on the size of the municipality (Intel Core i5-6200U, $2.4 \mathrm{GHz}$, and 4 Threads). Since wind power plays a significant role in this study, the process from Mainzer ${ }^{26}$ for selecting wind turbines is described here. First, areas in the municipality are determined where turbines can be placed. This involves excluding areas via minimum distance restrictions or via technical constraints, such as a slope greater than $20^{\circ}$. Then, based on a turbine database, the turbine types associated with the lowest LCOEs in the municipality are selected. The locations of these turbines are chosen using a heuristic that ensures that as many turbines as possible can be placed while maintaining the minimum distances between them (ellipse with the following dimensions: eight times the rotor diameter in the main wind direction; five times in the secondary wind direction). Repowering of wind turbines, which is expected to become very relevant for the wind industry, ${ }^{71}$ is neglected in the model.

$\mathrm{RE}^{3} \mathrm{ASON}$ further provides a deterministic model of optimal investment and dispatch for new energy conversion technologies at the municipality level. In the mixed-integer linear program, the optimal technology investment and unit commitment of all technologies as well as energy flows between districts are identified. The model serves to cope with the complexity resulting from the number and combinations of the individual measures and their dependencies that would otherwise not be feasible. Included in the model are the abovementioned energy supply technologies as well as measures, such as insulation, heating technologies, or appliances. A municipality under consideration is divided into districts, in which buildings are grouped into building types according to the TABULA building typology. ${ }^{72}$ The spatial resolution consists of these districts as nodes to which the input, such as heat and power demand, is assigned. In this study, the model is used to perform a long-term energy system optimization from 2021 to 2050, whereby each 10th year (i.e., 2021, 2030, 2040 , and 2050) is modeled explicitly and divided into 108 time slices (4 seasons, 3 day types, 9 time slices within each day). This means that investment decisions can be made every 10th year, as a trade-off between model accuracy and model complexity. The $\mathrm{RE}^{3} \mathrm{ASON}$ model is employed for minimizing the total discounted system costs in this study. Depending on the number of districts, the optimization years and the number of building types, the optimization process can take between a few hours and around 7 days (e.g., Intel Xeon E-1650, 3.2 GHz, 12 Threads or $2 \times$ Intel E5-2697, 2.4 GHz, 72 Threads). For example, an optimization from 2021 to 2050 for a municipality with 8 districts and 12 building types contains about 200,000 (in)equations, 150,000 variables, 700,000 non-zero entries, and 4,500 binary variables. Among the 10 municipalities analyzed, the optimizations for Steinbergkirche (cluster 10) took the most time with a total of $62 \mathrm{~h}$. Therefore, combined with the determination of the input parameters, an analysis of a large number of case studies would not be feasible within practicable computational resources.

In the RE ${ }^{3} \mathrm{ASON}$ model, the macroeconomic perspective of central planners who develop concepts for the design of energy systems in municipalities is applied. It takes into account all decision-relevant expenditures within the energy system, regardless of which actor is responsible for these expenditures. For example, the optimal investments of private households in new heating systems are determined from a system perspective without considering the economic viability of these investments from the perspective of the individual household. Within this macroeconomic perspective, taxes, subsidies, and levies are considered as a redistribution of costs and are therefore not included in the cost calculation. This means, for example, that the Renewable Energy Sources Act levy is not included in the electricity price for consumers, but at the same time the owners of RE plants do not receive any feed-in remuneration for electricity generation. The reason for this approach is that the legislative situation, which showed frequent changes in the past, cannot be assumed to be constant over the long-term time horizon of the model. Furthermore, this allows a neutral comparison between individual technologies and measures. Regarding the prices of the energy sources, the model only takes into account the costs of procurement and distribution as well as grid fees. ${ }^{26}$ Taxes and levies, which in 2019 accounted for about $52 \%$ of the household electricity price as well as about $26 \%$ of the natural gas price, ${ }^{73}$ are also regarded as redistribution of costs and are 
Table 5. Energy system LCOEs for the representative municipalities of the ten clusters in the Reference Scenario and the NoWind Scenario

\begin{tabular}{|c|c|c|c|}
\hline $\begin{array}{l}\text { Cluster and } \\
\text { municipality }\end{array}$ & $\begin{array}{l}\text { LCOEs } \\
\text { Reference } \\
\text { Scenario } \\
\text { (€-cent/kWh) }\end{array}$ & $\begin{array}{l}\text { LCOEs } \\
\text { NoWind } \\
\text { Scenario } \\
\text { (€-cent/kWh) }\end{array}$ & $\begin{array}{l}\text { Deviation } \\
(\%)\end{array}$ \\
\hline $\begin{array}{l}\text { Cluster } 1 \\
\text { (Gelbensande) }\end{array}$ & 10.6 & 16.3 & +54 \\
\hline $\begin{array}{l}\text { Cluster } 2 \\
\text { (Bad Kreuznach) }\end{array}$ & 19.3 & 20.8 & +8 \\
\hline $\begin{array}{l}\text { Cluster } 3 \\
\text { (Dänischenhagen) }\end{array}$ & 16.9 & 23.0 & +36 \\
\hline Cluster 4 (Warnow) & 10.5 & 16.5 & +57 \\
\hline Cluster 5 (Seckach) & 14.9 & 18.1 & +22 \\
\hline $\begin{array}{l}\text { Cluster } 6 \text { (Trebsen/ } \\
\text { Mulde) }\end{array}$ & 13.1 & 18.3 & +40 \\
\hline Cluster 7 (Nindorf) & 17.7 & 17.7 & +0 \\
\hline $\begin{array}{l}\text { Cluster } 8 \\
\text { (Rövershagen) }\end{array}$ & 13.9 & 17.7 & +27 \\
\hline Cluster 9 (Göhrde) & 8.9 & 14.7 & +65 \\
\hline $\begin{array}{l}\text { Cluster } 10 \\
\text { (Steinbergkirche) }\end{array}$ & 19.3 & 19.3 & +0 \\
\hline
\end{tabular}

therefore not considered in the economic evaluation. ${ }^{26}$ For further information about the model, including the calculation of the municipal RE potentials and the mathematical model formulation the reader is referred to McKenna et al., ${ }^{74}$ Weinand et al., ${ }^{75,67}$ and Mainzer. ${ }^{26}$

To be able to investigate energy systems until 2050, developments have been assumed for some input parameters. In Weinand et al., ${ }^{66}$ a methodology was presented to determine current electricity demands in the residential, commercial, and industrial sectors based on socio-economic parameters, such as population, area, number of companies, and number of employees. ${ }^{76}$ The result was a weighting matrix of indicators for determining the electricity demand. To estimate future demand, the development of the abovementioned socio-economic indicators between 2008 and 2018 was calculated. Assuming a linear development and using the weighting matrix, the annual development of electricity demand can thus be estimated (cf. annual change in Table 1).

For the future development of the costs for electricity procurement and transmission, the past development in Germany between 2006 and 2018 was assumed (mean of approximately $+2 \% / a$ ). ${ }^{77}$ This means, that the costs for electricity procurement and transmission would increase from about 15 $€$-cent/kWh in 2021 to approximately $26 €$-cent/kWh in 2050. Furthermore, cost reductions were assumed for technologies such as electricity storages (approximately $-4 \% / a),{ }^{78} \mathrm{PV}$ modules (approximately $\left.-2 \% / a\right),{ }^{79}$ wind turbines (approximately $-1 \% / a),{ }^{79}$ and deep geothermal energy systems (approximately $-0.5 \% / a){ }^{80}$ This study does not include a holistic view of all system developments, for example, the climate was assumed to stay constant. The development of $\mathrm{CO}_{2}$ emissions (without upstream chain) from electricity production has been assumed from $401 \mathrm{gCO}_{2} / \mathrm{kWh}$ in $2019^{81}$ to $26 \mathrm{gCO}_{2} / \mathrm{kWh}$ in $2050 .^{82}$ Further techno-economic assumptions regarding technologies can be found in Tables S1 and S2 in the supplemental information.

Energy system optimization

This section presents the structure and some of the most important equations of the $\mathrm{RE}^{3} \mathrm{ASON}$ optimization model. Tables 2,3 , and 4 list the sets and subsets, the parameters and the variables of the model, respectively.
The objective function $z$ of the $\mathrm{RE}^{3} \mathrm{ASON}$ model (Equation 1) includes the four indicators total discounted system costs $z^{c}$ (Equation 2), emissions $z^{e}$, net energy imports $z^{i}$, and primary energy demand $z^{p}$, as well as the associated weightings $W$ for these indicators. In this study, the weighting $W^{c}$ for costs is set to one and the other weightings to zero, i.e., the energy systems are optimized regarding total discounted system costs.

$$
\begin{gathered}
\operatorname{minz}=\left(W^{c} \cdot z^{c}+W^{e} \cdot z^{e}+W^{i} \cdot z^{j}+W^{p} \cdot z^{p}\right) \text { with } \\
W^{c}, W^{e}, W^{i}, W^{p} \in\{0 ; 1\} ;\left(W^{c}+W^{e}+W^{i}+W^{p}\right)=1 \\
z^{c}=\sum_{y \in M Y}\left(D F_{y} \cdot N Y_{y} \cdot\left(c_{y}^{e i}+c_{y}^{e t}+c_{y}^{e d}+c_{y}^{i a}+c_{y}^{f x}+c_{y}^{v r}+c_{y}^{e m}\right)\right) \quad \text { (Equation 1) }
\end{gathered}
$$

The total discounted system costs include costs for energy import $c^{e i}$ (Equation 3), transmission grid utilization $c^{\text {et }}$ (Equation 4), local energy distribution $c^{e d}$ (Equation 5), investment annuities $c^{\text {ia }}$ (Equation 6), fixed operating costs $c^{f x}$ (Equation 7), variable operating costs $c^{\text {vr }}$ (Equation 8), and emissions $c^{e m}$ (Equation 9). As stated before, taxes and subsidies are explicitly not considered: the model incorporates a macroeconomic perspective and taxes or subsidies are considered as a redistribution of costs with no impact on total welfare. In this study emission costs $C E$ are also not considered.

$$
C_{y}^{e i}=\sum_{t \in T S, e \in E C}\left(N T_{t} \cdot C F_{y, t, e} \cdot \sum_{d 1 \in D S^{e x}, d 2 \in D S^{e n}}\left(f l_{y, t, d 1, d 2, e}^{d}-f l_{y, t, d 2, d 1, e}^{d}\right)\right)
$$

$$
c_{y}^{e t}=\sum_{e \in E C}\left(C T_{y, e} \cdot \sum_{t \in T S, d 1 \in D S^{e x}, d 2 \in D S^{e n}}\left(N T_{t} \cdot\left(f l_{y, t, d 1, d 2, e}^{d}+f l_{y, t, d 2, d 1, e}^{d}\right)\right)\right)
$$

(Equation 4)

$C_{y}^{e d}=\sum_{e \in E C}\left(C D_{y, e} \cdot \sum_{t \in T S, e \in E C, d 1 \in D S^{e n}, d 2 \in D S^{e n}: d 1 \neq d 2}\left(N T_{t} \cdot\left(f l_{y, t, d 1, d 2, e}^{d}+f f_{y, t, d 2, d 1, e}^{d}\right)\right)\right)$ (Equation 5)

$$
\begin{aligned}
c_{y}^{i a}= & \sum_{d \in D S^{e n}, s \in S T, b \in B l, t c \in T C^{s s}: H G(d, s, b)}\left(A F_{t c} \cdot \sum_{y_{1} \in M Y: y_{1} \geq y_{0}, y_{1} \leq y, R L_{t c, y_{1}, y}>0}\right. \\
& \left(\operatorname { m i n } ( R L _ { t c , y _ { 1 } , y } , N Y _ { y } ) \cdot N B _ { y _ { 1 } , d , s , b } \cdot \left(b n i_{y_{1}, d, s, b, t, t c}^{B l} \cdot C l_{t c, y_{1}}\right.\right. \\
+ & \left.\left.\left.u c_{y_{1}, d, s, s, b, t c}^{B l} \cdot U I_{t c, y_{1}}\right)\right) / N Y_{y}\right) \\
& +\sum_{d \in D S^{e n}, t c \in T C^{\prime s}}\left(A F_{t c} \cdot \sum_{y_{1} \in M Y: y_{1} \geq y_{0}, y_{1} \leq y, R L_{t c, y y_{1}, y}>0}\right.
\end{aligned}
$$$$
\left.\left(\min \left(R L_{t c, y_{1}, y}, N Y_{y}\right) \cdot\left(b n i_{y_{1}, d, t c}^{D S} \cdot C l_{t c, y_{1}}+u c_{y_{1}, d, t c}^{D S} \cdot U I_{t c, y_{1}}\right)\right) / N Y_{y}\right)
$$

(Equation 6)

$$
c_{y}^{f x}=\sum_{d \in D S e n, s \in S T, b \in B l, t c \in T C^{s s}: H G(d, s, b)}\left(N B_{y, d, d, b} \cdot u s_{y, d, d, b, b, t c}^{B l} \cdot C X_{t c}\right)
$$$$
+\sum_{d \in D S^{e n}, t c \in T C^{\prime s}}\left(u s_{y, d, t c}^{D S} \cdot C X_{t c}\right)
$$

$$
\begin{aligned}
C_{y}^{v r}= & \sum_{t \in T C, d \in D S e n, s \in S T, b \in B l, t c \in T C^{s s}: H G(d, s, b)}\left(\left.N T_{t} \cdot N B_{y, d, s, b} \cdot a\right|_{y, t, d, s, b, t c} ^{B !} \cdot N H_{t} \cdot C V_{t c}\right) \\
& +\sum_{t \in T S, d \in D S \text { sen, }, c \in \in T C^{\prime s}}\left(\left.N T_{t} \cdot a\right|_{y, t, d, t c} ^{D S} \cdot N H_{t} \cdot C V_{t c}\right) \quad \text { (Equation 8) }
\end{aligned}
$$


Table 6. Fraction of municipalities, onshore wind potential, and energy demand in the total values for Germany for the three scenarios NoWind_75\%, NoWind_50\%, and NoWind_25\%, as well as information on $\Delta$ LCOEs and $\Delta \mathrm{CO}_{2}$ in these scenarios

\begin{tabular}{llll}
\hline Scenario & NoWind_75\% & NoWind_50\% & NoWind_25\% \\
\hline Fraction of municipality number (\%) & 75.0 & 50.0 & 25.0 \\
Fraction of onshore wind potential (\%) & 62.7 & 32.2 & 13.1 \\
Fraction of demand (\%) & 50.3 & 30.0 & 12.7 \\
Fraction of municipalities with $\Delta \mathrm{LCOEs}=0 €$-cent $/ \mathrm{kWh}(\%)$ & 5.8 & 7.9 & 12.4 \\
Fraction of municipalities with $\Delta \mathrm{LCOEs}>0 €$-cent $/ \mathrm{kWh}(\%)$ & 94.2 & 92.1 & 87.6 \\
Mean $\Delta \mathrm{LCOEs}(€-$ cent $/ \mathrm{kWh})$ & 2.73 & 2.47 & 2.09 \\
Fraction of municipalities with $\Delta \mathrm{CO}_{2}=0 \mathrm{gCO}_{2} / \mathrm{kWh}(\%)$ & 7.7 & 10.3 & 14.9 \\
Fraction of municipalities with $\Delta \mathrm{CO}_{2}>0 \mathrm{gCO}_{2} / \mathrm{kWh}(\%)$ & 92.3 & 89.7 & 85.1 \\
Mean $\Delta \mathrm{CO}_{2}\left(\mathrm{gCO}_{2} / \mathrm{kWh}\right)$ & 74.2 & 65.6 & 56.8 \\
\hline
\end{tabular}

$$
C_{y}^{e m}=\sum_{t \in T S, d \in D S^{e n}, m \in E M}\left(N T_{t} \cdot e m_{y, t, d, m} \cdot C E_{y, t, m}\right)
$$

Emissions include model-endogenous emissions em (Equation 10) and model-exogenous emissions $E M^{e x}$. The exogenous emissions may be specified by the user, e.g., to incorporate emissions from currently not covered sectors, such as transport. In this study, $E M^{e x}$ are set to zero.

$$
\begin{aligned}
e m_{y, t, d, e}= & \sum_{s \in S T, b \in B l, t c \in T C^{s s}: H G(d, s, b)}\left(N B_{y, d, s, b} \cdot a l_{y, t, d, s, b, t c}^{B l} \cdot E R_{t c, m} \cdot N H_{t}\right) \\
& +\sum_{t c \in T C^{\prime s}}\left(a l_{y, t, d, t c}^{D S} \cdot E R_{t c, m} \cdot N H_{t}\right)
\end{aligned}
$$$$
\forall y \in M Y, t \in T S, d \in D S^{e n}, m \in E M
$$

(Equation 10)

The decommissioned units $u d a$ are a combination of model-endogenous decommissioning $u d$ as well as units from the initially existing stock IS and units built by the model uc that reach the end of their respective lifetimes: Equation 11 for buildings and Equation 12 for districts.

$$
\begin{gathered}
u d a_{y, d, s, b, t c}^{B l}=\sum_{y_{1} \in A Y: y_{1}<y, R L\left(t c, y_{1}, y-1\right)>0, R L\left(t c, y_{1}, y\right) \leq 0}\left(I S_{y_{1}, d, s, b, t c}^{B I}\right) \\
+\sum_{y_{1} \in M Y: y_{1}<y, R L\left(t c, y_{1}, y-1\right)>0, R L\left(t c, y_{1}, y\right) \leq 0}\left(u c_{y_{1}, d, s, b, t c}^{B I}\right)+u d_{y_{1}, d, s, b, t c}^{B l}
\end{gathered}
$$

$\forall y \in M Y, d \in D S^{e n}, s \in S T, b \in B l, t c \in T C^{s s}: H G(d, s, b)$

(Equation 11)

$$
\begin{gathered}
u d a_{y, d, t c}^{D S}=\sum_{y_{1} \in A Y: y_{1}<y, R L\left(t c, y_{1}, y-1\right)>0, R L\left(t c, y_{1}, y\right) \leq 0}\left(I S_{y_{1}, d, t c}^{D S}\right) \\
+\sum_{y_{1} \in M Y: y_{1}<y, R L\left(t c, y_{1}, y-1\right)>0, R L\left(t c, y_{1}, y\right) \leq 0}\left(u c_{y_{1}, d, t c}^{D S}\right)+u d_{y_{1}, d, t c}^{D S}
\end{gathered}
$$

$\forall y \in M Y, d \in D S^{e n}, t c \in T C^{l s}$

(Equation 12)

The stock of each technology us per model year is determined by the initially existing stock of units as well as all commissioned and decommissioned units: Equation 13 for buildings and Equation 14 for districts.

$$
u s_{y, d, s, b, t c}^{B l}=\sum_{y_{1} \in A Y: y_{1}<y}\left(I S_{y_{1}, d, s, b, t c}^{B l}\right)+\sum_{y_{1} \in M Y: y_{1}<y}\left(u c_{y_{1}, d, s, b, t c}^{B I}-u d a_{y_{1}, d, s, b, t c}^{B l}\right)
$$$$
\forall y \in M Y, d \in D S^{e n}, s \in S T, b \in B l, t c \in T C^{s s}: H G(d, s, b)
$$

(Equation 13)

$$
\begin{aligned}
& u s_{y, d, t c}^{D S}=\sum_{y_{1} \in A Y: y_{1}<y}\left(I S_{y_{1}, d, t c}^{D S}\right)+\sum_{y_{1} \in M Y: y_{1}<y}\left(u c_{y_{1}, d, t c}^{D S}-u d a_{y_{1}, d, t c}^{d s}\right) \\
& \forall y \in M Y, d \in D S^{e n}, t c \in T C^{/ s}
\end{aligned}
$$

Equation 15 and Equation 16 fix the activity level al for technologies, such as $\mathrm{PV}$, to their pre-determined activity levels $A L^{f x}$ from the simulations in the first step, scaled with the number of installed units us on building or district level, respectively.

$$
\begin{array}{ll}
a l_{y, t, d, s, b, t c}^{B l}=u s_{y, d, s, b, t c}^{B l} \cdot A L_{y, t, t c}^{f x} & \text { (Equation 15) } \\
\forall y \in M Y, t \in T S, d \in D S^{e n}, s \in S T, b \in B l, t c \in T C^{f x}: H G(d, s, b) & \\
a l_{y, t, d, t c}^{D S}=u s_{y, d, t c}^{D S} \cdot A L_{y, t, t c}^{f x}, \forall y \in M Y, t \in T S, d \in D S^{e n}, t c \in T C^{f x} & \text { (Equation 16) }
\end{array}
$$

Some of the most important restrictions are the energy balance equations-Equation 17 for building level, Equation 18 for district level-which guarantee that the energy demand has to be matched by an equivalent supply at all times. While for the residential sector, electricity and heat demand are covered, for the industrial and commercial sector only electricity is supplied.

$$
\begin{aligned}
& \sum_{t c \in T C^{s s}}\left(a l_{y, t, d, s, b, t c}^{B l} \cdot I O_{t c, e} \cdot N H_{t}\right)+f l_{y, t, d, s, b, e}^{b}-D M_{y, t, d, s, b, e} \cdot N H_{t}=0 \\
& \forall y \in M Y, t \in T S, d \in D S^{e n}, s \in S T, b \in B I, e \in E C^{b}: H G(d, s, b)
\end{aligned}
$$

(Equation 17)

$$
\sum_{t c \in T C^{\prime s}}\left(a l_{y, t, d, t c}^{D S} \cdot 1 O_{t c, e} \cdot N H_{t}\right)+\sum_{d 1 \in D S: d 1 \neq d} f l_{y, t, d 1, d, e}^{d}-\sum_{d 1 \in D S: d 1 \neq d} f l_{y, t, d, d 1, e}^{d}
$$

$-\sum_{s \in S T, b \in B l: H G(d, s, b)}\left(N B_{y, d, s, b} \cdot f l_{y, t, d, s, b, e}^{b}\right)-N H_{t} \cdot\left(I N D_{y, t, d, e}+C O D_{y, t, d, e}\right)=0$

$\forall y \in M Y, t \in T S, d \in D S^{e n}, e \in E C^{b}$

(Equation 18)

Furthermore, the allowed energy flow between districts $f l^{d}$ (Equation 19) and from district to building level $\mathrm{fl}^{\mathrm{b}}$ can be restricted (minimum and maximum energy flows for all buildings in a district as well as for each single building: Equation 20, Equation 21, Equation 22, Equation 23).

$$
f l_{y, t, d, d 1, e}^{d} / N H_{t}<=F D_{y, d, d 1, e}^{\max } \forall y \in M Y, t \in T S, d \in D S, d 1 \in D S, e \in E C: d 1 \neq d
$$

(Equation 19)

$$
\begin{aligned}
& \sum_{s \in S T, b \in B l}\left(N B_{y, d, s, b} \cdot f l_{y, t, d, s, b, e}^{b}\right) / N H_{t}<=F B_{y, d, e}^{\max } \\
& \forall y \in M Y, t \in T S, d \in D S^{e n}, e \in E C
\end{aligned}
$$

$$
\begin{aligned}
& \sum_{s \in S T, b \in B l}\left(\left.N B_{y, d, s, b} \cdot f\right|_{y, t, d, s, b, e} ^{b}\right) / N H_{t}>=F B_{y, d, e}^{\min } \\
& \forall y \in M Y, t \in T S, d \in D S^{e n} e \in E C
\end{aligned}
$$


A

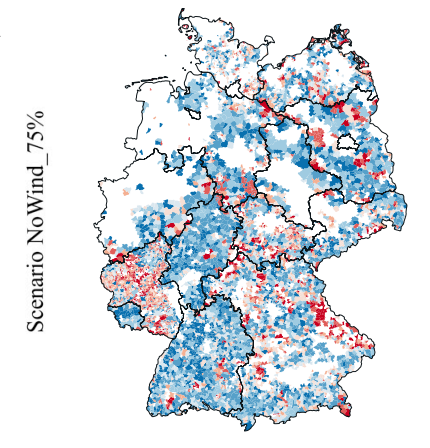

B

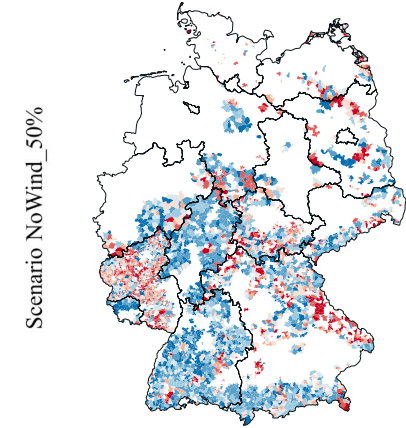

C

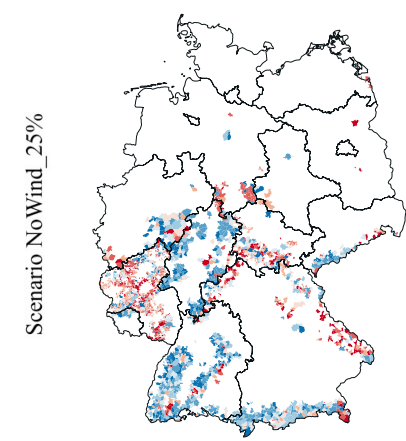

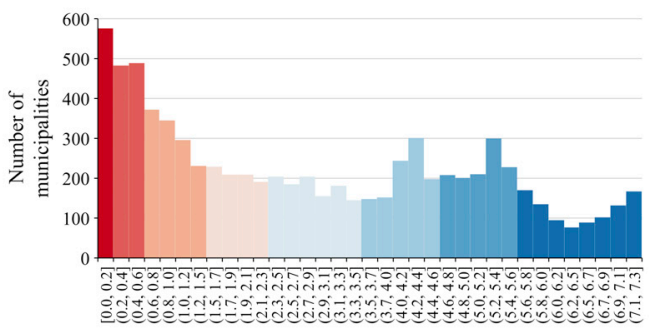

$\triangle \mathrm{LCOE}[\epsilon$-cent/kWh]

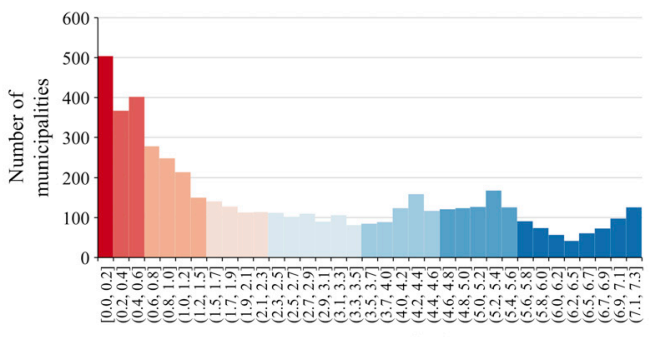

$\triangle \mathrm{LCOE}[€$-cent $/ \mathrm{kWh}]$

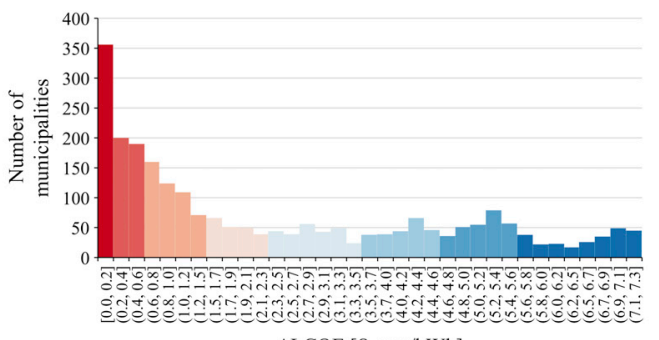

Figure 5. Distribution of $\Delta$ LCOEs resulting from the application of the regression model for the 11,131 municipalities

The $\triangle \mathrm{LCOEs}$ in comparison with the Reference Scenario result for specific municipalities, in which the onshore wind potential is restricted. The colors of the municipalities in the map on the left side of the figure correspond to the values in the histogram on the right side. In (A), onshore wind is excluded in all municipalities with a mean scenicness quality of at least 4.15 , in (B) for a mean scenicness quality of at least 4.98 , and in (C) for a scenicness quality of at least 5.86 .

nario) and one without onshore wind (NoWind Scenario). The results of both scenarios were used in regression analyses in order to get results for all German municipalities.

After correlation analysis across all variables from the cluster analysis, the following variables remained as independent variables for the regression: energy demands for the industrial sector, commercial sector, and residential sector, as well as the potential of onshore wind, solar PV, biomass, and deep geothermal energy. As deep geothermal energy was not included in the optimal energy systems of the $\mathrm{RE}^{3} \mathrm{ASON}$ results, this variable was subsequently excluded. The LCOEs (cf. Equation 26 and Figure 2), $\triangle L C O E s$ (cf. Equation 27 and Figure 5), and specific emissions $\mathrm{ACO}_{2}$ (cf. Equation 28 and Figure S5) were used as independent variables in three different regressions.

$\Delta \mathrm{LCOE}[\epsilon-\mathrm{cent} / \mathrm{kWh}]$

$$
L C O E=\frac{\sum_{y=1}^{Y} \frac{C A P E X_{y}+O P E X_{y}}{(1+i)^{Y}}}{\sum_{y=1}^{Y} \frac{E D_{y}}{(1+i)^{Y}}}
$$

(Equation 26)

$$
f l_{y, t, d, s, b, e}^{b} / N H_{t}<=F B_{y, d, e}^{\max }
$$

$\forall y \in M Y, t \in T S, d \in D S^{e n}, s \in S T, b \in B I, e \in E C: H G(d, s, b) \quad$ (Equation 22)

$$
f l_{y, t, d, s, b, e}^{b} / N H_{t}>=F B_{y, d, e}^{\min } \forall y \in M Y, t \in T S, d \in D S^{e n}, s \in S T, b \in B l, e \in E C
$$

(Equation 23)

Inequalities-Equation 24 and Equation 25-restrict the maximum allowed quantities of certain technologies, e.g., due to potential restrictions or due to the unavailability of a technology at certain time. These inequalities have been used to exclude onshore wind in the NoWind Scenario.

$$
u s_{y, d, s, b, t c}^{B l}<=U A_{y, d, s, b, t c}^{B l} \forall y \in M Y, d \in D S^{e n}, s \in S T, b \in B I, t c \in T C^{s s}: H G(d, s, b)
$$

(Equation 24)

$$
u s_{y, d, t c}^{D S}<=U A_{y, d, t c}^{D S}
$$

$\forall y \in M Y, d \in D S^{e n}, t c \in T C^{s}$

(Equation 25)

\section{Regression analysis}

The $\mathrm{RE}^{3} \mathrm{ASON}$ model has been used to analyze the ten representative municipalities from the cluster analysis in two scenarios, one with (Reference Sce-

$$
\begin{gathered}
\Delta L C O E=L C O E_{R E F}+L C O E_{\text {NoWind }} \\
\Delta C O_{2}=C O_{2, R E F}+C O_{2, \text { NoWind }}=\frac{\sum_{y=1}^{\gamma} C O_{2, R E F, y}-C O_{2, \text { NoWind } y}}{\sum_{y=1}^{Y} E D_{y}} . \quad \text { (Equation 28) }
\end{gathered}
$$

The LCOEs and the specific emissions $\mathrm{CO}_{2}$ are calculated depending on the investments (CAPEX), the operational and maintenance costs (OPEX), the total $\mathrm{CO}_{2}$, and the total energy demand $(E D)$ of a municipality in a year $(y)$. The interest rate $(i)$ is assumed to be $5 \%$. The $\triangle L C O E$ s and specific $\triangle C_{2}$ are determined by the difference of the results between Reference Scenario (REF) and NoWind Scenario (NoWind).

Due to the small number of energy system results, a k-fold cross-validation following the leave-one-out procedure is applied in the regression analysis in order to identify the best regression model. ${ }^{66}$ The results of these cross-validations are shown in Figure S6. In all three cases, a model based on the Gaussian process regression was selected on the basis of the error measures and the coefficient of determination.

\section{Public acceptance and scenicness}

The term public acceptance is defined in this paper based on Wüstenhagen et al.'s ${ }^{83}$ framework, with acceptance subject, object, and context according to Lucke, ${ }^{84}$ and by the definition of acceptance based on Schweizer-Ries. ${ }^{85}$ In this article we employ scenicness data to represent the public's (subjects) appreciation of the landscape. The focus of this study is on onshore wind 
energy (object) in German municipalities (context). In terms of the dimensions explored, we mainly consider community acceptance in this study, as we do not have a representative sample of the population to derive insights about their preferences. Similarly, while we touch on market acceptance, we only do this indirectly in the sense that local resistance to proposed wind farms might result in them not being built.

In Roth et al., ${ }^{25}$ scenicness quality values for the whole territory of Germany $\left(>380,000 \mathrm{~km}^{2}\right.$ ) have been assessed. These are based on more than 10,000 photographs, of which 822 were selected by an expert group. This remaining sample of photographs was rated by a representative group of more than 3,500 respondents, resulting in more than 44,000 landscape assessments with scenic quality values between 1 (low scenicness) and 9 (high scenicness). Besides the geo-tagging, the position of the camera, the field of view, and the horizontal direction, GIS was used for a visibility analysis on the national digital elevation model. In total, 18 different independent variables were used in the last step, the regression analysis, to obtain scenic quality values for every $1 \mathrm{~km}^{2}$ of the German territory. ${ }^{25}$ The resulting scenicness values are distributed heterogeneously across the German territory (cf. Figure 1), with the highest scenicness in areas with steep terrain, natural landscapes, and low presence of human interference. ${ }^{25}$ These areas include the Alps in the south, the Black Forest in the southwest, and the Bavarian Forest in the southeast. Low scenicness, on the other hand, is found in areas with high human interference, such as cities. As demonstrated in Figure 1, the area-weighted mean scenicness is subsequently employed for each municipality.

For this, the scenicness values resolved on $1 \mathrm{~km}^{2}$ were aggregated as mean values at the municipal level (cf. Figure 1). This approach was chosen because our model does not explicitly consider the type and route of grid infrastructure. However, these networks would also have an impact on the landscape and could therefore lead to rejection in public. ${ }^{86}$ This aggregation in the municipalities results in only a small mean deviation of 0.55 from the higher-resolution values. The mean of the 11,131 resulting scenicness values in Germany is 5.1 and can therefore be classified as mediocre. In the three scenarios NoWind_75\%, NoWind_50\%, and NoWind_25\%, onshore wind is excluded as an option in municipalities where the mean scenicness is higher than the three quartiles at $4.15,4.98$, and 5.86 , respectively.

Existing wind turbines

The wind turbines currently installed and operated in Germany were determined with the help of OpenStreetMap data. The overpass ${ }^{87}$ query is as follows:

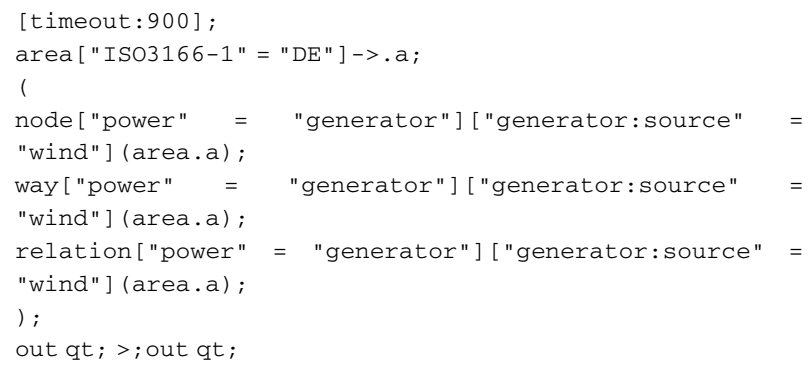

In OpenStreetMap, about 28,500 wind turbines are recorded, which corresponds to $97 \%$ of the real stock number of about 29,500 turbines. ${ }^{88}$ These wind turbines were intersected with the German municipalities with the help of the geographic information system QGIS $^{89}$ to analyze in which municipalities turbines have already been installed.

\section{SUPPLEMENTAL INFORMATION}

Supplemental information can be found online at https://doi.org/10.1016/j. patter.2021.100301.

\section{ACKNOWLEDGMENTS}

The authors would like to thank H.G. Schwarz-von Raumer as well as the German Federal Agency for Nature Conservation for providing the scenicness data. Large parts of the methodology of this study were developed during the first author's three-and-a-half year PhD study period. The first author would therefore like to thank the three funding bodies during this period: the German Federal Ministry of Education and Research (BMBF) within the Kopernikus Project ENSURE "New ENergy grid StructURes for the German Energiewende" (funding reference: FKZ 03SFK1N0), the PhD College "Energy and Resource Efficiency" (ENRES) from the Federal State of Baden-Wuerttemberg, as well as the German Federal Ministry for Economic Affairs and Energy (BMWi) within the TrafoKommune project (funding reference: 03EN3008F).

\section{AUTHOR CONTRIBUTIONS}

Conceptualization, J.M.W. and R.M.; methodology, J.M.W., R.M., and M.K.; formal analysis, J.M.W.; data curation, J.M.W.; writing - original draft, J.M.W.; writing - review \& editing, R.M., J.M.W., and F.S.; writing - interactive feedback, R.M., M.K., F.S., and W.F.; visualization, J.M.W.; project administration, R.M. and W.F.; funding acquisition, R.M., W.F., and J.M.W.

\section{DECLARATION OF INTERESTS}

The authors declare no competing interests.

Received: February 25, 2021

Revised: May 6, 2021

Accepted: June 7, 2021

Published: June 28, 2021

\section{REFERENCES}

1. UNFCCC (2021). The Paris Agreement. https://unfccc.int/process-andmeetings/the-paris-agreement/the-paris-agreement.

2. Krog, L., and Sperling, K. (2019). A comprehensive framework for strategic energy planning based on Danish and international insights. Energy Strategy Rev. 24, 83-93.

3. Roberts, D. (2008). Thinking globally, acting locally-institutionalizing climate change at the local government level in Durban, South Africa. Environ. Urbanization 20, 521-537.

4. Adesanya, A.A., Sidortsov, R.V., and Schelly, C. (2020). Act locally, transition globally: grassroots resilience, local politics, and five municipalities in the United States with 100\% renewable electricity. Energy Res. Soc. Sci. $67,101579$.

5. Arentsen, M., and Bellekom, S. (2014). Power to the people: local energy initiatives as seedbeds of innovation? Energ Sustain. Soc. 4. https://doi. org/10.1186/2192-0567-4-2.

6. Marinakis, V., Doukas, H., Xidonas, P., and Zopounidis, C. (2017). Multicriteria decision support in local energy planning: an evaluation of alternative scenarios for the Sustainable Energy Action Plan. Omega $69,1-16$.

7. Weinand, J.M. (2020). Reviewing municipal energy system planning in a bibliometric analysis: evolution of the research field between 1991 and 2019. Energies 13, 1367.

8. Brisbois, M.C. (2020). Decentralised energy, decentralised accountability? Lessons on how to govern decentralised electricity transitions from multi-level natural resource governance. Glob. Transitions 2, 16-25.

9. Wyse, S.M., and Hoicka, C.E. (2019). "By and for local people": assessing the connection between local energy plans and community energy. Local Environ. 24, 883-900.

10. Reusswig, F., Braun, F., Heger, I., Ludewig, T., Eichenauer, E., and Lass, W. (2016). Against the wind: local opposition to the German Energiewende. Utilities Policy 41, 214-227.

11. Suškevičs, M., Eiter, S., Martinat, S., Stober, D., Vollmer, E., Boer, C.L.de, and Buchecker, M. (2019). Regional variation in public acceptance of wind energy development in Europe: what are the roles of planning procedures and participation? Land Use Policy 81, 311-323. 
12. Petrova, M.A. (2016). From NIMBY to acceptance: toward a novel framework-VESPA-for organizing and interpreting community concerns. Renew. Energy 86, 1280-1294.

13. Molnarova, K., Sklenicka, P., Stiborek, J., Svobodova, K., Salek, M., and Brabec, E. (2012). Visual preferences for wind turbines: location, numbers and respondent characteristics. Appl. Energy 92, 269-278.

14. Wolsink, M. (2018). Co-production in distributed generation: renewable energy and creating space for fitting infrastructure within landscapes. Landscape Res. 43, 542-561.

15. Lütkehaus, I., Salecker, H., and Adlunger, K. (2021). Potenzial der Windenergie an Land (Potential of onshore wind energy). https:// www.umweltbundesamt.de/sites/default/files/medien/378/publikationen/ potenzial_der_windenergie.pdf.

16. Wehrle, S., Schmidt, S., and Mikovits, C. (2020). The Cost of Undisturbed Landscapes. https://arxiv.org/abs/2006.08009.

17. McKenna, R., Weinand, J.M., Mulalic, I., Petrovic, S., Mainzer, K., Preis, T., and Moat, H.S. (2021). Scenicness assessment of onshore wind sites with geotagged photographs and impacts on approval and cost-efficiency. Nat. Energy. https://doi.org/10.1038/s41560-021-00842-5.

18. Price, J., Mainzer, K., Petrovic, S., Zeyringer, M., and McKenna, R. (2020). The implications of landscape visual impact on future highly renewable power systems: a case study for Great Britain. IEEE Trans. Power Syst. 1. https://doi.org/10.1109/TPWRS.2020.2992061.

19. Roddis, P., Carver, S., Dallimer, M., Norman, P., and Ziv, G. (2018). The role of community acceptance in planning outcomes for onshore wind and solar farms: an energy justice analysis. Appl. Energy 226, 353-364.

20. Baxter, J. (2017). Energy justice: participation promotes acceptance. Nat. Energy 2. https://doi.org/10.1038/nenergy.2017.128.

21. Liebe, U., Bartczak, A., and Meyerhoff, J. (2017). A turbine is not only a turbine: the role of social context and fairness characteristics for the local acceptance of wind power. Energy Policy 107, 300-308.

22. Langer, K., Decker, T., and Menrad, K. (2017). Public participation in wind energy projects located in Germany: which form of participation is the key to acceptance? Renew. Energy 112, 63-73.

23. Weinand, J.M., McKenna, R., and Fichtner, W. (2019). Developing a municipality typology for modelling decentralised energy systems. Utilities Policy 57, 75-96.

24. European Commission (2020). 2050 long-term strategy. https://ec.europa. eu/clima/policies/strategies/2050_en.

25. Roth, M., Hildebrandt, S., Röhner, S., Tilk, C., Schwarz-von Raumer, H.-G., Roser, F., and Borsdorff, M. (2018). Landscape as an area as perceived by people: empirically-based nationwide modelling of scenic landscape quality in Germany. J. Digital Landscape Architecture, 129-137.

26. Mainzer, K. (2019). Analyse und Optimierung urbaner Energiesysteme Entwicklung und Anwendung eines übertragbaren Modellierungswerkzeugs zur nachhaltigen Systemgestaltung (Dissertation. Karlsruher Institut für Technologie, Karlsruhe. Institut für Industriebetriebslehre und Industrielle Produktion (IIP)). https:// publikationen.bibliothek.kit.edu/1000092481.

27. Agora Energiewende. (2020). Die Energiewende im Stromsektor. https:// www.agora-energiewende.de/fileadmin2/Projekte/2019/Jahresauswertung 2019/A-EW_Die-Energiewende-im-Stromsektor-2019_Foliensatz.pdf.

28. McKenna, R., Hollnaicher, S., and Fichtner, W. (2014). Cost-potential curves for onshore wind energy: a high-resolution analysis for Germany. Appl. Energy 115, 103-115.

29. UBA (2020). Energiebedingte Emissionen (Energy-Related Emissions). https://www.umweltbundesamt.de/daten/energie/energiebedingteemissionen\#energiebedingte-treibhausgas-emissionen.

30. Drücke, J., Borsche, M., James, P., Kaspar, F., Pfeifroth, U., Ahrens, B., and Trentmann, J. (2021). Climatological analysis of solar and wind energy in Germany using the Grosswetterlagen classification. Renew. Energy $164,1254-1266$
31. Langer, K., Decker, T., Roosen, J., and Menrad, K. (2016). A qualitative analysis to understand the acceptance of wind energy in Bavaria. Renew. Sustain. Energy Rev. 64, 248-259.

32. Tröndle, T., Lilliestam, J., Marelli, S., and Pfenninger, S. (2020). Trade-offs between geographic scale, cost, and infrastructure requirements for fully renewable electricity in Europe. Joule 4, 1929-1948.

33. Bertsch, V., Hall, M., Weinhardt, C., and Fichtner, W. (2016). Public acceptance and preferences related to renewable energy and grid expansion policy: empirical insights for Germany. Energy 114, 465-477.

34. Betakova, V., Vojar, J., and Sklenicka, P. (2015). Wind turbines location: how many and how far? Appl. Energy 151, 23-31.

35. Schumacher, K., Krones, F., McKenna, R., and Schultmann, F. (2019). Public acceptance of renewable energies and energy autonomy: a comparative study in the French, German and Swiss Upper Rhine region. Energy Policy 126, 315-332.

36. Sonnberger, M., and Ruddat, M. (2017). Local and socio-political acceptance of wind farms in Germany. Technol. Soc. 51, 56-65.

37. van der Horst, D. (2007). NIMBY or not? Exploring the relevance of location and the politics of voiced opinions in renewable energy siting controversies. Energy Policy 35, 2705-2714.

38. Sütterlin, B., and Siegrist, M. (2017). Public acceptance of renewable energy technologies from an abstract versus concrete perspective and the positive imagery of solar power. Energy Policy 106, 356-366.

39. Liebe, U., and Dobers, G.M. (2019). Decomposing public support for energy policy: what drives acceptance of and intentions to protest against renewable energy expansion in Germany? Energy Res. Soc. Sci. 47, 247-260

40. Azarova, V., Cohen, J., Friedl, C., and Reichl, J. (2019). Designing local renewable energy communities to increase social acceptance: evidence from a choice experiment in Austria, Germany, Italy, and Switzerland. Energy Policy 132, 1176-1183.

41. Ioannidis, R., and Koutsoyiannis, D. (2020). A review of land use, visibility and public perception of renewable energy in the context of landscape impact. Appl. Energy 276, 115367.

42. Vuichard, P., Stauch, A., and Wüstenhagen, R. (2020). Keep it local and low-key: social acceptance of alpine solar power projects. Renew. Sustain. Energy Rev. 110516.

43. Dobers, G.M. (2019). Acceptance of biogas plants taking into account space and place. Energy Policy 135, 110987.

44. Schumacher, K., and Schultmann, F. (2017). Local acceptance of biogas plants: a comparative study in the trinational Upper Rhine region. Waste Biomass Valor. 8, 2393-2412.

45. Welder, L., Ryberg, D.S., Kotzur, L., Grube, T., Robinius, M., and Stolten, D. (2018). Spatio-temporal optimization of a future energy system for power-to-hydrogen applications in Germany. Energy 158, 1130-1149.

46. Schnuelle, C., Wassermann, T., Fuhrlaender, D., and Zondervan, E. (2020). Dynamic hydrogen production from PV and wind direct electricity supply-modeling and techno-economic assessment. Int. J. Hydrogen Energy 45, 29938-29952.

47. Fasihi, M., and Breyer, C. (2020). Baseload electricity and hydrogen supply based on hybrid PV-wind power plants. J. Clean. Prod. 243, 118466.

48. Ueckerdt, F., Hirth, L., Luderer, G., and Edenhofer, O. (2013). System LCOE: what are the costs of variable renewables? Energy 63, 61-75.

49. Scholz, Y., Gils, H.C., and Pietzcker, R.C. (2017). Application of a highdetail energy system model to derive power sector characteristics at high wind and solar shares. Energy Econ. 64, 568-582.

50. Patrizio, P., Pratama, Y.W., and Dowell, N.M. (2020). Socially equitable energy system transitions. Joule 4, 1700-1713.

51. Sasse, J.-P., and Trutnevyte, E. (2019). Distributional trade-offs between regionally equitable and cost-efficient allocation of renewable electricity generation. Appl. Energy 254, 113724.

52. Sasse, J.-P., and Trutnevyte, E. (2020). Regional impacts of electricity system transition in Central Europe until 2035. Nat. Commun. 11, 4972. 
53. Drechsler, M., Egerer, J., Lange, M., Masurowski, F., Meyerhoff, J., and Oehlmann, M. (2017). Efficient and equitable spatial allocation of renewable power plants at the country scale. Nat. Energy 2. https://doi.org/10. 1038/nenergy.2017.124.

54. World Energy Council (2020). World Energy Trilemma Index. https://www worldenergy.org/transition-toolkit/world-energy-trilemma-index.

55. BWE (2020). EEG 2021. https://www.wind-energie.de/aktuelles/eegaktuell/.

56. Xiong, B., Predel, J., Crespo del Granado, P., and Egging-Bratseth, R (2020). Spatial flexibility in redispatch: supporting low carbon energy systems with Power-to-Gas. Appl. Energy 283, 116201. https://doi.org/10. 1016/j.apenergy.2020.116201.

57. Joos, M., and Staffell, I. (2018). Short-term integration costs of variable renewable energy: wind curtailment and balancing in Britain and Germany. Renew. Sustain. Energy Rev. 86, 45-65.

58. Kerr, S., Johnson, K., and Weir, S. (2017). Understanding community benefit payments from renewable energy development. Energy Policy 105, 202-211.

59. Hevia-Koch, P., and Klinge Jacobsen, H. (2019). Comparing offshore and onshore wind development considering acceptance costs. Energy Policy 125, 9-19.

60. BMWi. (2020). Frischer Wind für den Ausbau der Erneuerbaren. https://www.bmwi-energiewende.de/EWD/Redaktion/Newsletter/2020/06/ Meldung/topthema.html.

61. Duda, R.O., and Hart, P.E. (1976). Pattern Classification and Scene Analysis (Wiley).

62. Milligan, G.W. (1980). An examination of the effect of six types of error perturbation on fifteen clustering algorithms. Psychometrika 45, 325-342.

63. Milligan, G.W. (1981). A Monte Carlo study of thirty internal criterion measures for cluster analysis. Psychometrika 46, 187-199.

64. Dunn†, J.C. (1974). Well-separated clusters and optimal fuzzy partitions. J. Cybernetics 4, 95-104.

65. Mainzer, K., Killinger, S., McKenna, R., and Fichtner, W. (2017) Assessment of rooftop photovoltaic potentials at the urban level using publicly available geodata and image recognition techniques. Solar Energy 155, 561-573.

66. Weinand, J.M., Ried, S., Kleinebrahm, M., McKenna, R., and Fichtner, W. (2020). Identification of potential off-grid municipalities with $100 \%$ renewable energy supply for future design of power grids. IEEE Trans. Power Syst.

67. Weinand, J.M., McKenna, R., Kleinebrahm, M., and Mainzer, K. (2019). Assessing the contribution of simultaneous heat and power generation from geothermal plants in off-grid municipalities. Appl. Energy 255, 113824.

68. McKenna, R., Pfenninger, S., Heinrichs, H., Schmidt, J., Staffell, I., Gruber, K., Hahmann, A.N., Jansen, M., Klingler, M., Landwehr, N., et al. (2021). Reviewing Methods and Assumptions for High-Resolution Large-Scale Onshore Wind Energy Potential Assessments, arXiv. https://arxiv.org/ abs/2103.09781.

69. Hübner, G., Pohl, J., Hoen, B., Firestone, J., Rand, J., Elliott, D., and Haac, R. (2019). Monitoring annoyance and stress effects of wind turbines on nearby residents: a comparison of U.S. and European samples. Environ. Int. 132, 105090

70. Weinand, J.M., McKenna, R., and Mainzer, K. (2019). Spatial high-resolution socio-energetic data for municipal energy system analyses. Sci. Data 6. https://doi.org/10.1038/s41597-019-0233-0.
71. Kitzing, L., Jensen, M.K., Telsnig, T., and Lantz, E. (2020). Multifaceted drivers for onshore wind energy repowering and their implications for energy transition. Nat. Energy 5, 1012-1021.

72. IWU (2015). Deutsche Wohngebäudetypologie. Beispielhafte Maßnahmen zur Verbesserung der Energieeffizienz von typischen Wohngebäuden (zweite erweiterte Auflage). https://www.episcope.eu/downloads/public/ docs/brochure/DE_TABULA_TypologyBrochure_IWU.pdf.

73. Bundesnetzagentur. (2019). Informationen zu Strom- und Gaspreisen für Haushaltskunden. https://www.bundesnetzagentur.de/DE/Sachgebiete/ ElektrizitaetundGas/Verbraucher/PreiseRechnTarife/preiseundRechnungennode.html.

74. McKenna, R., Bertsch, V., Mainzer, K., and Fichtner, W. (2018). Combining local preferences with multi-criteria decision analysis and linear optimization to develop feasible energy concepts in small communities. Eur. J. Oper. Res. 268, 1092-1110.

75. Weinand, J.M., Kleinebrahm, M., McKenna, R., Mainzer, K., and Fichtner, W. (2019). Developing a combinatorial optimisation approach to design district heating networks based on deep geothermal energy. Appl. Energy 251, 113367.

76. Statistische Ämter des Bundes und der Länder. (2020). Regionaldatenbank Deutschland. https://www.regionalstatistik.de/genesis/online/data.

77. BMWi. (2019). Alle Tarife mengengewichteter Elektrizitätspreis für Haushaltskunden. https://www.bmwi.de/Redaktion/DE/Infografiken/ Energie/strompreisbestandteile.html.

78. Schmidt, O., Melchior, S., Hawkes, A., and Staffell, I. (2019). Projecting the future levelized cost of electricity storage technologies. Joule 3, 81-100.

79. Danish Energy Agency (2020). Technology Data. https://ens.dk/sites/ens. dk/files/Statistik/technology_data_catalogue_for_el_and_dh_-_0009.pdf.

80. Tsiropoulos, I., Tarvydas, D., and Zucker, A. (2018). Cost Development of Low Carbon Energy Technologies. https://publications.jrc.ec.europa. eu/repository/bitstream/JRC109894/cost_development_of_low_carbon_ energy_technologies_v2.2_final_online.pdf.

81. Statista. (2020). Entwicklung des CO2-Emissionsfaktors für den Strommix in Deutschland in den Jahren 1990 bis 2019. https://de.statista. com/statistik/daten/studie/38897/umfrage/co2-emissionsfaktor-fuer-denstrommix-in-deutschland-seit-1990/\#: :text=Im\%20Jahr\%202019\%20 wird\%20der,mit\%20kleinen\%20Ausnahmen\%20kontinuierlich\%20ab.

82. Greiner, B., and Hermann, H. (2016). Sektorale Emissionspfade in Deutschland Bis 2050 - Stromerzeugung. https://www.oeko.de/ oekodoc/2545/2016-072-de.pdf.

83. Wüstenhagen, R., Wolsink, M., and Bürer, M.J. (2007). Social acceptance of renewable energy innovation: an introduction to the concept. Energy Policy 35, 2683-2691.

84. Lucke, D. (1995). Akzeptanz. Legitimität in der Abstimmungsgesellschaft (Wiesbaden: VS Verlag für Sozialwissenschaften).

85. Schweizer-Ries, P. (2008). Energy sustainable communities: environmental psychological investigations. Energy Policy 36, 4126-4135.

86. Komendantova, N., and Battaglini, A. (2016). Beyond Decide-AnnounceDefend (DAD) and Not-in-My-Backyard (NIMBY) models? Addressing the social and public acceptance of electric transmission lines in Germany. Energy Res. Soc. Sci. 22, 224-231.

87. OpenStreetMap contributors. (2020). Overpass Turbo. https://overpassturbo.eu/.

88. BWE (2020). Zahlen und Fakten. https://www.wind-energie.de/themen/ zahlen-und-fakten/.

89. QGIS Association (2020). QGIS - A Free and Open Source Geographic Information System. https://www.qgis.org/en/site/. 